\title{
Brain Region-Specific Trafficking of the Dopamine Transporter
}

\author{
Ethan R. Block, ${ }^{1}$ Jacob Nuttle, ${ }^{2}$ Judith Joyce Balcita-Pedicino, ${ }^{2}$ John Caltagarone, ${ }^{1}{ }^{-S i m o n}$ C. Watkins, ${ }^{1}$ \\ Susan R. Sesack, ${ }^{2}$ and Alexander Sorkin ${ }^{1}$ \\ ${ }^{1}$ Department of Cell Biology, University of Pittsburgh School of Medicine, Pittsburgh, Pennsylvania 15261, and ${ }^{2}$ Department of Neuroscience, University of \\ Pittsburgh Dietrich School of Arts and Sciences, Pittsburgh, Pennsylvania 15260
}

The dopamine (DA) transporter (DAT) controls dopaminergic neurotransmission by removing extracellular DA. Although DA reuptake is proposed to be regulated by DAT traffic to and from the cell surface, the membrane trafficking system involved in the endocytic cycling of DAT in the intact mammalian brain has not been characterized. Hence, we performed immunolabeling and quantitative analysis of the subcellular and regional distribution of DAT using the transgenic knock-in mouse expressing hemagglutinin (HA) epitope-tagged DAT (HA-DAT) and by using a combination of electron microscopy and a novel method for immunofluorescence labeling of HA-DAT in acute sagittal brain slices. Both approaches demonstrated that, in midbrain somatodendritic regions, HA-DAT was present in the plasma membrane, endoplasmic reticulum, and Golgi complex, with a small fraction in early and recycling endosomes and an even smaller fraction in late endosomes and lysosomes. In the striatum and in axonal tracts between the midbrain and striatum, HA-DAT was detected predominantly in the plasma membrane, and quantitative analysis revealed increased DAT density in striatal compared with midbrain plasma membranes. Endosomes were strikingly rare and lysosomes were absent in striatal axons, in which there was little intracellular HA-DAT. Acute administration of amphetamine in vivo $(60 \mathrm{~min})$ or to slices ex vivo $(10-60 \mathrm{~min})$ did not result in detectable changes in DAT distribution. Altogether, these data provide evidence for regional differences in DAT plasma membrane targeting and retention and suggest a surprisingly low level of endocytic trafficking of DAT in the striatum along with limited DAT endocytic activity in somatodendritic areas.

Key words: dopamine; electron microscopy; endocytosis; transporter

\section{Significance Statement}

The dopamine transporter (DAT) is the key regulator of the dopamine neurotransmission in the CNS. In the present study, we developed a new approach for studying DAT localization and dynamics in intact neurons in acute sagittal brain slices from the knock-in mouse expressing epitope-tagged DAT. For the first time, the fluorescence imaging analysis of DAT was combined with the immunogold labeling of DAT and quantitative electron microscopy. In contrast to numerous studies of DAT trafficking in heterologous expression systems and dissociated cultured neurons, studies in intact neurons revealed a surprisingly low amount of endocytic trafficking of DAT at steady state and after acute amphetamine treatment and suggested that non-vesicular transport could be the main mechanism establishing DAT distribution within the dopaminergic neuron.

\section{Introduction}

Dopaminergic neurons control aspects of mood, cognition, and movement and are involved in the pathogenesis and treatment of

Received April 10, 2015; revised July 16, 2015; accepted Aug. 7, 2015.

Author contributions: E.R.B., S.R.S., and A.S. designed research; E.R.B., J.N., J.J.B.-P., J.C., S.C.W., and A.S. performed research; E.R.B., J.N., S.R.S., and A.S. analyzed data; E.R.B., S.R.S., and A.S. wrote the paper.

This work was supported by National Institutes of Health/National Institute on Drug Abuse Grants DA014204 (A.S., E.R.B., J.C.) and F32DA034408 (E.R.B.). We are grateful to Dr. Mads Larsen, Callen Wallace, and Mara Sullivan (Center for Biological Imaging, University of Pittsburgh) for assistance with large-area confocal imaging, structured illumination microscopy, and cryoelectron microscopy, respectively. We also thank Dr. R. Prekeris (University of Colorado) for the Syntaxin 13 antibody. The anti-LAMP1 1D4B antibody developed by August J. Thomas was obtained from the Developmental Studies Hybridoma Bank, created by the National Institute of Child Health and a variety of disorders, including drug addiction, depression, and Parkinson's disease (Gainetdinov and Caron, 2003; Spiga et al., 2008; Wise, 2008; Willuhn et al., 2010). A primary regulator of dopaminergic neurotransmission is the dopamine (DA) trans-

Human Development of the National Institutes of Health and maintained at the University of lowa (Department of Biology).

\section{The authors declare no competing financial interests.}

Correspondence should be addressed to either of the following: Susan R. Sesack, Department of Neuroscience, University of Pittsburgh Dietrich School of Arts and Sciences, Pittsburgh, PA 15260, E-mail: sesack@pitt.edu; or Alexander Sorkin, Department of Cell Biology, University of Pittsburgh School of Medicine, 3500 Terrace Street, Pittsburgh, PA 15261, E-mail: sorkin@pitt.edu.

DOI:10.1523/JNEUROSCI.1391-15.2015

Copyright $\odot 2015$ the authors $\quad 0270-6474 / 15 / 3512845-14 \$ 15.00 / 0$ 
porter (DAT; Giros et al., 1991; Jaber et al., 1997; Kristensen et al., 2011). The psychostimulants amphetamine, cocaine, and methylphenidate elicit dramatic behavioral phenotypes in large part by targeting DAT directly and increasing extracellular DA. Identifying mechanisms of DAT regulation not only contributes to our broader understanding of DA physiology but also suggests therapeutic options for treatment of DA pathologies, such as drug addiction.

Somatodendritic regions of DA neurons are located in the midbrain substantia nigra (SN) and ventral tegmental area. From there, DA neurons send bundles of axons rostrally to the dorsal striatum and nucleus accumbens, as well as to the frontal cortex (Ciliax et al., 1999). Because DA reuptake requires the presence of DAT in the plasma membrane (PM), proper subcellular trafficking and localization of the transporter is crucial for its function. Studies using primary neuronal cultures suggest that DAT passes through the biosynthetic pathway to the PM and undergoes constitutive endocytosis (Melikian 2004; Miranda et al., 2004; Sorkina et al., 2006; Eriksen et al., 2009; Zahniser and Sorkin, 2009). However, there is disagreement on whether endocytosed DAT is preferentially targeted to lysosomes for degradation or recycled back to the PM (Melikian, 2004; Chen et al., 2010; Eriksen et al., 2010; Rao et al., 2011). Furthermore, PM delivery (recycling) and/or endocytosis can be enhanced by a variety of stimuli, including cocaine, amphetamine, and the protein kinase $\mathrm{C}$ (PKC) activator phorbol 12-myristate 13-acetate, findings that are supported by biochemical studies with primary cultured neurons and ex vivo tissue preparations, such as synaptosomes or brain slices (Huff et al., 1997; Vaughan et al., 1997; Melikian and Buckley, 1999; Hoover et al., 2007; Cremona et al., 2011; Gabriel et al., 2013). In contrast, PKC-mediated endocytosis of DAT has not been observed in several studies using primary neuronal cultures (Eriksen et al., 2009; Rao et al., 2012).

Little is known about the general organization of the endocytic trafficking system in the intact DA neuron. A number of studies using electron microscopy (EM) to gain valuable insight into DAT distribution and function in the rat brain have revealed that DAT is found at the PM in axons, although it may be excluded from active zones (Nirenberg et al., 1996, 1997; Hersch et al., 1997; Ciliax et al., 1999). Although these original EM studies provided the first characterizations of DAT localization in the intact DA neuron, the immunohistochemical methods used in these studies are sometimes associated with sparse labeling that does not allow for quantitative analysis of DAT localization. Thus, a number of important questions have remained unanswered. First, is DAT present in a higher concentration in striatal axons, presynaptic terminals in particular, compared with dendrites and the soma? If so, the existence of a specific axon/synapse targeting mechanism can be predicted. Second, is there a large fraction of DAT in endosomes and lysosomes? A large endolysosomal pool of DAT would be indicative of substantial constitutive endocytosis and other vesicular trafficking processes within the DA neuron.

For the present studies, we have examined DAT subcellular localization and regulation using a knock-in mouse that expresses a DAT with a hemagglutinin (HA) epitope inserted into the second extracellular loop (HA-DAT; Rao et al., 2012). The HA epitope is highly efficient for EM localization studies, permitting quantitative analysis and the identification of intracellular DAT pools. The HA epitope also provides a readily accessible epitope to observe transporter dynamics by fluorescence microscopy in acute brain slice preparations.

\section{Materials and Methods}

Antibodies and chemicals. Mouse monoclonal antibodies against the HA epitope HA11 (16B12) were from BioLegend (mms-101p); specificity of HA11 for DA neurons in HA-DAT mice has been established previously (Rao et al., 2012). Rat monoclonal antibodies against the $\mathrm{N}$ terminus of DAT were from Millipore (MAB369; characterized by Hersch et al., 1997; Garzón and Pickel, 2006), goat polyclonal antibodies against the C terminus of DAT (Salvatore et al., 2003) were from Santa Cruz Biotechnology, rat monoclonal anti-lysosome-associated membrane protein 1 (LAMP1) antibodies were from the University of Iowa Developmental Studies Hybridoma Bank (1D4B; deposited to the Developmental Studies Hybridoma Bank by J. T. August, Johns Hopkins School of Medicine, Baltimore, MD; Chen et al., 1985), mouse monoclonal anti-early endosomal antigen 1 (EEA.1) antibodies were from BD Biosciences (610457; Mu et al., 1995), rabbit anti-Syntaxin 13 (Stx13) antibodies were from Rytis Prekeris (University of Colorado, Denver, CO; Prekeris et al., 1999), and rabbit anti-tyrosine hydroxylase (TH) antibodies were from EMD Millipore (AB152). Fluorophore-conjugated secondary antibodies were from Jackson ImmunoResearch, and gold-conjugated secondary antibodies were from Aurion (800.022). The specificity and optimal conditions of labeling by all antibodies were determined based on the maximal difference between the immunofluorescence signal in the presence of a primary antibody and the background fluorescence in the absence of a primary antibody (replaced by corresponding nonspecific IgG). In addition, specificity and conditions for specific labeling of dopaminergic neurons with HA11, TH, and DAT antibodies were established based on the lack of labeling of nondopaminergic areas of the brain, cross-labeling of the same neurons by these antibodies, and detection of the same bands by Western blotting (HA11 and DAT antibodies). The specificity of antibodies to endosomal markers and optimal labeling conditions were additionally determined based on the presence of strong specific signals in cell bodies that exhibited the typical vesicular shape and perinuclear localization of endosomal compartments. All other reagents and supplies were from Thermo Fisher Scientific unless noted otherwise.

Preparation of acute brain slices. All experimental procedures involving the use of laboratory mice were approved by the Institutional Animal Care and Use Committee. Four- to 8-week-old HA-DAT mice of either sex were killed by $\mathrm{CO}_{2}$ asphyxiation, followed by decapitation. Brains were removed and submerged into an ice slush of oxygenated artificial CSF (ACSF; in mm: $124 \mathrm{NaCl}, 4 \mathrm{KCl}, 1.25 \mathrm{NaH}_{2} \mathrm{PO}_{4}, 25.7 \mathrm{NaHCO}_{3}, 1.2$ $\mathrm{MgSO}_{4}, 2.45 \mathrm{CaCl}_{2}, 11$ dextrose, and 0.15 ascorbic acid). After an initial sagittal cut along the midline, 0.8 - $\mathrm{mm}$-thick slices were made using microtome blades and a stainless steel slicing block. Slices were allowed to recover in ACSF for $60 \mathrm{~min}$ at room temperature. For labeling of the cell-surface pool of HA-DAT (Figs. 1,2), slices were incubated in ACSF at room temperature with $1 \mu \mathrm{g} / \mathrm{ml}$ anti-HA antibodies for $1 \mathrm{~h}$. For labeling of the cell-surface and endocytosed pool of HA-DAT (see Fig. 8), slices were incubated in ACSF at $37^{\circ} \mathrm{C}$ with $1 \mu \mathrm{g} / \mathrm{ml}$ anti-HA antibodies for $1 \mathrm{~h}$ in the absence or presence of $100 \mu \mathrm{M} d$-amphetamine hemisulfate. After removing unbound $\mathrm{HA}$ antibodies, slices were fixed for $2 \mathrm{~h}$ in ACSF with freshly prepared $4 \%$ paraformaldehyde (Electron Microscopy Sciences).

Immunohistochemical analysis of fixed brain slices. Paraformaldehydefixed acute slices (above) or slices cut as described above but allowed to recover for $20 \mathrm{~min}$ before paraformaldehyde fixation were subjected to additional processing. Fixative was removed by washing in PBS, and slices were permeabilized by the addition of $0.3 \%$ Triton X-100 in PBS for $30 \mathrm{~min}$. Appropriate dilutions of primary antibodies were applied by overnight incubation at $4^{\circ} \mathrm{C}$. DAPI and fluorophore-conjugated secondary antibodies were applied for $1 \mathrm{~h}$ at room temperature before imaging.

Cell culture experiments. Human HEK293A cells were purchased from Invitrogen. A previously described CFP-HA-DAT [N-terminally cyan fluorescent protein (CFP)-tagged DAT that contains an HA epitope in the second extracellular loop; Vina-Vilaseca and Sorkin, 2010] was transfected at the time of seeding onto coverslips using Lipofectamine 2000 (Invitrogen) according to the instructions of the manufacturer. Two days after transfection, cells were incubated with $1 \mu \mathrm{g} / \mathrm{ml}$ anti-HA antibodies for $30 \mathrm{~min}$ at $37^{\circ} \mathrm{C}$ in the absence or presence of $100 \mu \mathrm{M} d$-amphetamine. Subsequently, cells were washed, fixed for $30 \mathrm{~min}$ with $4 \%$ paraformal- 

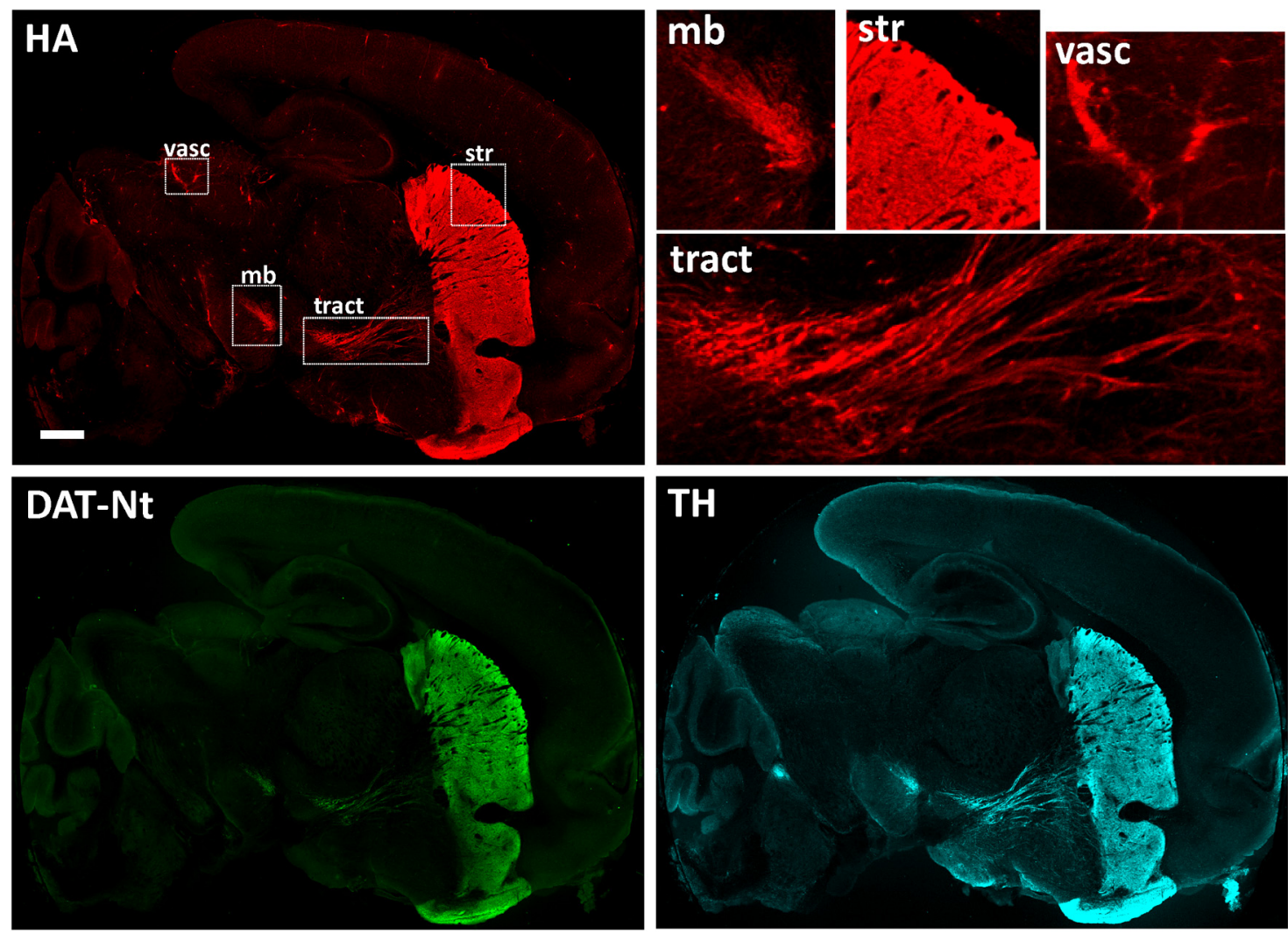

Figure 1. Distribution of HA-DAT on the sagittal slice from mouse brain. Sagittal slices were incubated with $\mathrm{HA11}$ for $1 \mathrm{~h}$ at room temperature, fixed, permeabilized, and labeled with TH and DAT-Nt antibodies, followed by secondary antibody specific to mouse, rat, or rabbit, and conjugated with Cy3 (HA, red), Alexa Fluor 488 (DAT-Nt, green), or Cy5 (TH, cyan), respectively. Multiple regions were imaged using a scanning confocal system and assembled in a single montage image. Insets represent high-magnification and high-contrast images of the regions of striatum (str), midbrain (mb), tracts (tract), and vasculature (vasc; anti-mouse host immunoreactivity) indicated by white rectangles. Scale bar, $2 \mathrm{~mm}$.

dehyde, permeabilized with $0.1 \%$ Triton X-100 for $5 \mathrm{~min}$, and incubated with fluorophore-conjugated goat anti-mouse antibodies before imaging.

Confocal fluorescence microscopy and image analysis. Large-area imaging was performed by acquiring multiple images through a $2 \times$ objective using a Nikon A1 scanning confocal microscope. The images were assembled in a single whole-slice montage image using Nikon Elements software.

To obtain high resolution three-dimensional (3D) images of the DA neurons in the brain slices, a $z$ stack of confocal images was acquired $10-40 \mu \mathrm{m}$ in from the cut face of the slice (to avoid debris from the slicing procedure while maintaining good resolution). The imaging system used was a spinning-disk confocal system based on a Zeiss Axio Observer Z1 inverted fluorescence microscope [with $63 \times$ Plan Apo PH, 1.4 numerical aperture (NA)], equipped with a computer-controlled Spherical Aberration Correction unit, Yokogawa CSU-X1, Vector photomanipulation module, Photometrics Evolve 16-bit EMCCD camera, HQ2 cooled CCD camera, environmental chamber, and piezo stage controller and lasers (405, 445, 488, 515,561 , and $640 \mathrm{~nm}$; Intelligent Imaging Innovations), all controlled by SlideBook 6 software (Intelligent Imaging Innovations). Typically, up to 10-40 serial two-dimensional confocal images were recorded at $300-400 \mathrm{~nm}$ intervals. Colocalization of the DAT with endocytic markers was determined by identifying clear overlapping structures that could be followed in multiple $z$ planes.

To compare quantitatively the density of HA-DAT in different brain regions (Fig. 2C), the slices were incubated with HA11 antibody, fixed, and labeled with secondary antibody as described above. $z$ stacks of 14 confocal images were acquired at $400 \mathrm{~nm}$ intervals starting at $10 \mu \mathrm{m}$ distance from the slice surface. Voxels containing HA-DAT were selected in each 3D image using automatic segmentation (Otsu algorithm), and a mean fluorescence intensity was determined after background subtrac- tion. For visual comparison of the fluorescence intensities of different structures in the DA neurons, high-resolution images are presented in the pseudocolor mode (Fig. 2B). In this mode, the fluorescence intensity is displayed stretched between identical low and high renormalization values, according to a temperature-based lookup table, with black (cold) indicating low values and red (hot) indicating high values. In these images, data with fluorescence values greater than the high threshold of the saturation channel are displayed at full saturation, whereas data values below the low threshold (background) are displayed with no saturation (i.e., black).

Structured illumination microscopy. Slices prepared and fixed as described above were imaged on an N-SIM (Nikon) super-resolution microscopy system with lateral $(x, y)$ resolution of $\sim 120 \mathrm{~nm}$ and axial $(z)$ resolution of $\sim 240 \mathrm{~nm}$, nearly double that of a conventional optical microscope. Images were collected on an inverted Nikon ECLIPSE Ti-E equipped with a $100 \times$ oil-immersion (1.49 NA) objective and Andor Technology iXon DU897 EM CCD camera. The 3D-SIM image $z$ stacks were processed and reconstructed in NIS Elements.

$E M$, immunocytochemistry, and image analysis. Pilot studies were performed on nine mice of either sex to determine the optimal fixation protocol for maximizing HA-DAT immunolabeling without substantially compromising morphological integrity. All mice were anesthetized with sodium pentobarbital (60 mg/kg, i.p.) and then treated for $15 \mathrm{~min}$ with $1 \mathrm{~g} / \mathrm{kg}$ sodium diethyldithiocarbamate (intraperitoneally) to chelate any endogenous zinc that might produce spurious gold-silver labeling (Veznedaroglu and Milner 1992). Mice were then perfused transcardially with one of the following fixatives made in $0.1 \mathrm{~m}$ phosphate buffer, $\mathrm{pH}$ 7.4: (1) 4\% paraformaldehyde; (2) 4\% paraformaldehyde together with glutaraldehyde ranging from 0.05 to $2 \%$; or (3) $2 \%$ paraformaldehyde with $3.75 \%$ acrolein. The majority of data collected for the present study was obtained from animals perfused with $4 \%$ paraformaldehyde and $1 \%$ glutaraldehyde as the optimal fixative. 
A
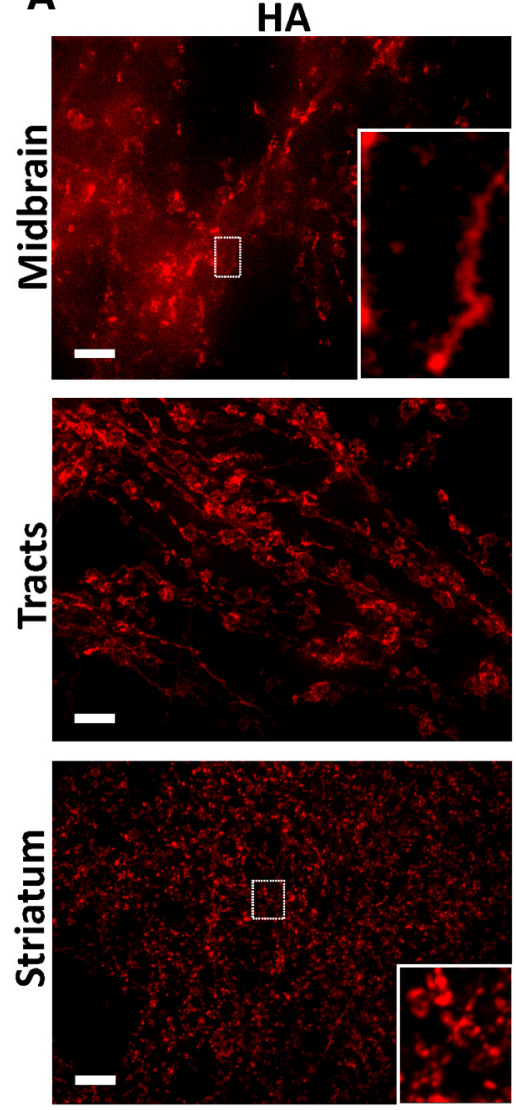

DAT-Nt
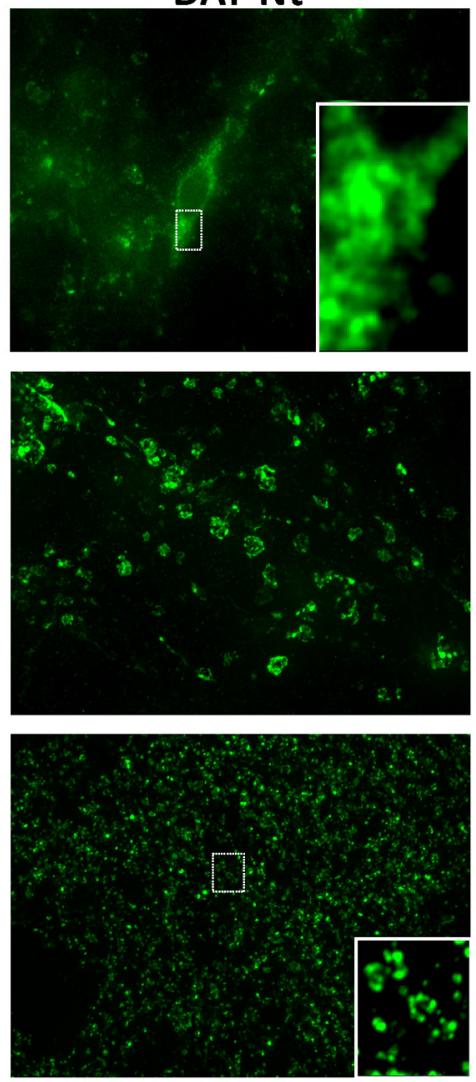

Merge
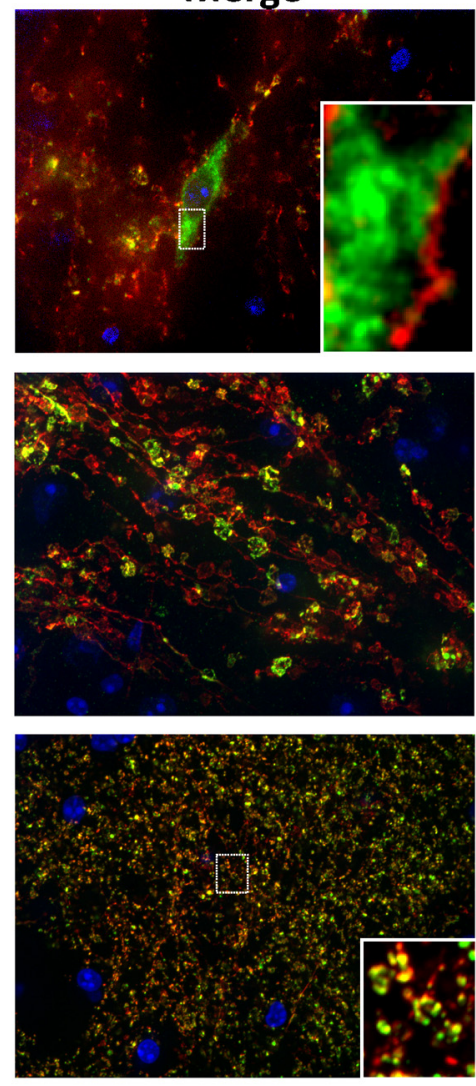

B
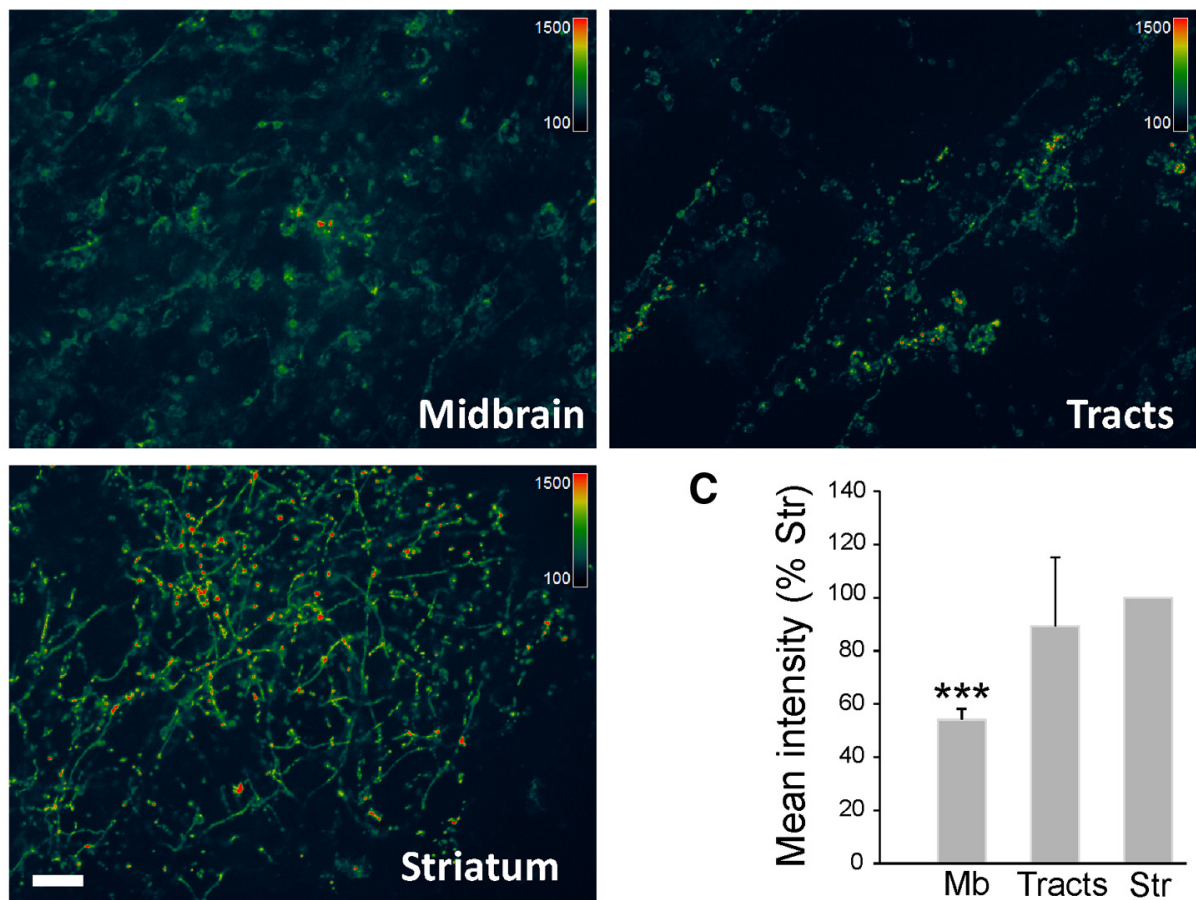

C

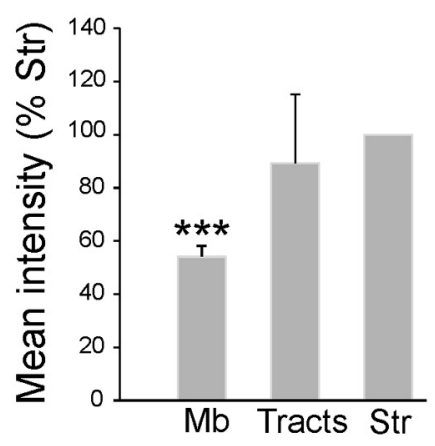

Figure 2. Subcellular distribution of HA-DAT on sagittal slices. A, Slices were incubated with HA11 for $1 \mathrm{~h}$ at room temperature, fixed, permeabilized, and labeled with DAT-Nt antibodies, followed by secondary antibody specific to mouse or rat, and conjugated with Cy3 (HA, red) and Alexa Fluor 488 (DAT-Nt, green), respectively. Cell nuclei were stained with DAPI (blue). $3 \mathrm{D}$ images were acquired using a spinning-disk confocal system through $488 \mathrm{~nm}, 561 \mathrm{~nm}$, and DAPI channels. Individual optical sections are presented. Insets are high-contrast images of the regions indicated by white rectangles to illustrate labeling of the PM and ER in the midbrain soma and an overlap of HA and DAT-Nt labeling in striatum. B, Pseudocolor images of striatum, tracts, and midbrain acquired at the same imaging settings and presented at the same intensity scale as described in Materials and Methods. The first section (10 $\mu \mathrm{m}$ from the edge of the slices) of the $z$ stack is presented for striatum and midbrain, whereas maximal projection image is presented for tracts (to better visualize tracts). C, Quantification of the mean intensities of the 3D images of HA11 fluorescence in the striatum (Str), tracts (Tracts), and midbrain (Mb) was performed as described in Materials and Methods. The bar graphs represent mean \pm SD values from three independent experiments, each five to seven $3 \mathrm{D}$ images. ${ }^{* * *} p=0.001$, significant difference from striatum. Scale bars, $10 \mu \mathrm{m}$. 

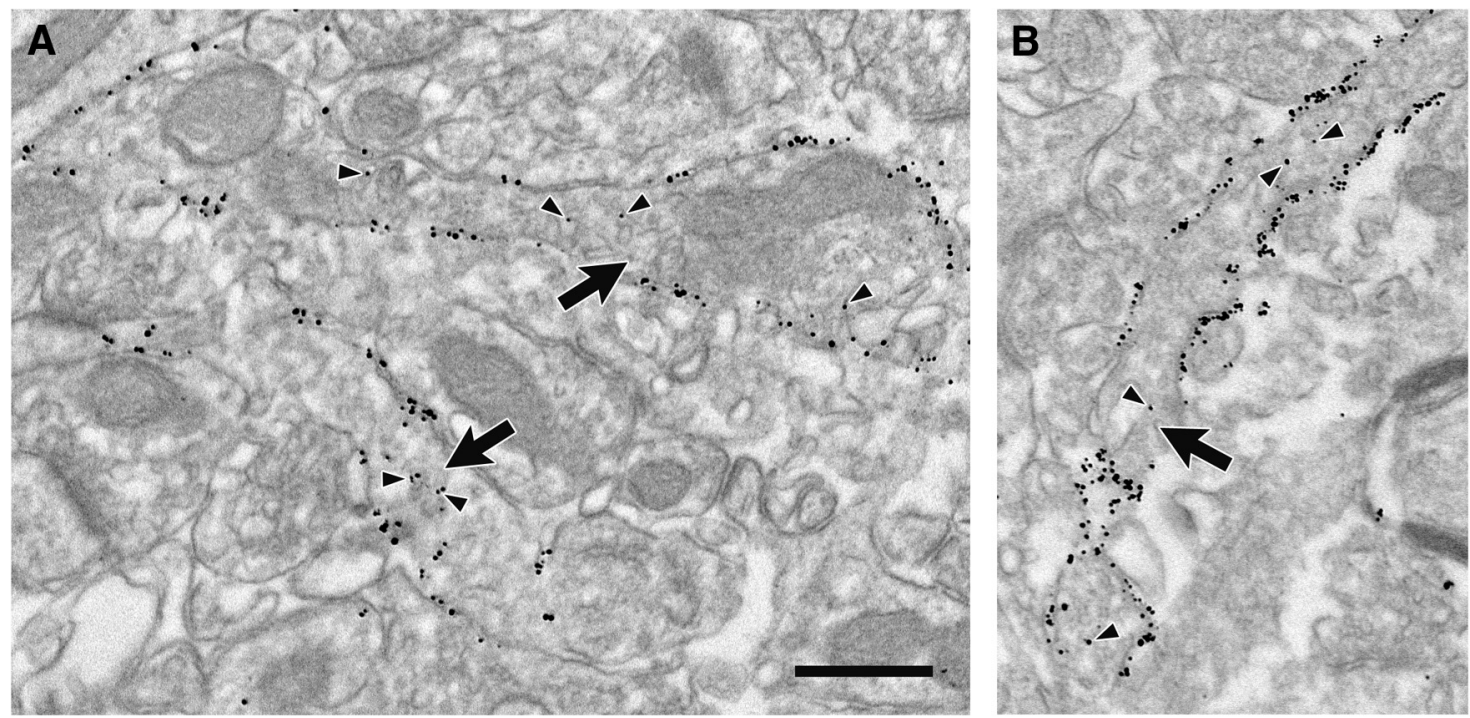

Figure 3. High density of HA-DAT labeling in the striatum. $\boldsymbol{A}, \boldsymbol{B}$, Electron micrographs from mouse dorsal striatum illustrating axons (large arrows) with extensive immunogold-silver labeling for HA-DAT in tissue fixed with 4\% paraformaldehyde and $0.05 \%$ glutaraldehyde. Although morphological preservation is compromised in this weak fixative, the efficiency of labeling is high and localized mostly to the PM. Arrowheads indicate occasional gold-silver particles within the interior of the axon. Note that nonspecific labeling in the neuropil adjacent to these axons is scant. Scale bar, $0.5 \mu \mathrm{m}$.

To examine the effect of amphetamine, four 6- to 8-week-old male mice (20-25 g) were used, and $d$-amphetamine hemisulphate was dissolved in $0.9 \%$ saline $(0.3 \mathrm{mg} / \mathrm{ml})$. Two mice each were injected intraperitoneally with either amphetamine $(3 \mathrm{mg} / \mathrm{kg})$ or an equivalent volume of saline (control). Forty-five minutes later, animals were anesthetized, treated with zinc chelator, and perfused with fixative as described above, with fixation occurring $\sim 1 \mathrm{~h}$ after amphetamine administration. Brains were postfixed for 30-60 min, sectioned through the midbrain and striatum at $50 \mu \mathrm{m}$ on a vibratome, and then treated for $30 \mathrm{~min}$ with $1 \%$ sodium borohydride in $0.1 \mathrm{M}$ phosphate buffer to terminate fixation. After extensive rinsing, sections were then treated to a freeze-thaw protocol in which they were incubated in cryoprotectant, frozen at $-80^{\circ} \mathrm{C}$, and then thawed in cryoprotectant. Tissue was then transferred to $0.1 \mathrm{M}$ Tris-buffered saline (TBS), pH 7.6, and blocked in 3\% normal donkey serum, $1 \%$ bovine serum albumin, and $0.04 \%$ Triton X-100 in TBS. The sections were then incubated for $\sim 36 \mathrm{~h}$ at $4^{\circ} \mathrm{C}$ in monoclonal anti-HA antibody (HA11). After extensive rinsing in TBS, sections were then transferred to $0.01 \mathrm{M}$ PBS, $\mathrm{pH} 7.4$, and blocked in blocking solution: $3 \%$ normal donkey serum, $0.8 \%$ bovine serum albumin, and $0.1 \%$ coldwater fish-skin gelatin (Aurion) in PBS. Tissue was then transferred to blocking solution containing 1:50 goat anti-mouse IgG conjugated with $0.8 \mathrm{~nm}$ gold (Aurion). After overnight incubation in secondary antibody, sections were then rinsed in blocking solution, followed by PBS. Tissue was then treated for 10 min with $2.5 \%$ glutaraldehyde in PBS and again rinsed. For silver enhancement, sections were transferred to 1:10 enhanced conditioning solution (ECS; Aurion) before being placed in R-Gent SE-EM reagents (Aurion) for $\sim 2.5 \mathrm{~h}$. After rinsing in 1:10 ECS, sections were then transferred to $0.1 \mathrm{M}$ phosphate buffer.

Tissue preparation for EM included incubation for $30 \mathrm{~min}$ in $1 \%$ osmium tetroxide in phosphate buffer, followed by rinsing and then dehydration through increasing alcohol solutions and propylene oxide. Tissue was plasticized overnight using a 1:1 mixture of propylene oxide and epoxy resin (Embed-812; Electron Microscopy Sciences) and then for $2 \mathrm{~h}$ in straight epoxy resin. Sections were solidified in resin between sheets of commercial plastic at $60^{\circ} \mathrm{C}$ for $72 \mathrm{~h}$. Ultrathin sections $(\sim 60$ $\mathrm{nm}$ ) through the striatum and $\mathrm{SN}$ were cut from the surface of this tissue and collected onto copper 400-mesh grids (open spacing, $3250 \mu \mathrm{m}^{2}$ ). Sections were then counterstained with uranyl acetate and lead citrate.

Tissue was examined on an FEI Morgagni transmission electron microscope by randomly scanning and photographing representative images at the tissue-plastic interface at which antibody penetration was maximal. Labeled profiles were included in the sample only if they con- tained a minimum of three gold-silver particles, although the majority of profiles had considerably more than three particles. Within the striatum, HA-DAT-labeled axons, some of which formed synapses onto spines or dendrites, were selected for analysis, whereas in the $\mathrm{SN}$, somata, and proximal and distal dendrites labeled for HA-DAT were selected, many of which received synaptic input. Approximately $9000-17,000 \mu \mathrm{m}^{2}$ tissue was examined per animal in the striatum, resulting in 382 micrographs. For the SN, $\sim 8000-16,000 \mu \mathrm{m}^{2}$ was scanned per mouse, which produced 232 micrographs.

Digital electron micrographs of profiles in the sample were analyzed using Neurolucida Morphometrics software (MBF Bioscience). The PMs of the selected profiles were traced to determine area and perimeter, and diameter was assessed manually as the widest part of the short axis of each profile (Sesack et al., 1998). Two different markers were used to differentiate gold-silver particles within $20 \mathrm{~nm}$ of the PM versus all other particles that lay within the cytoplasm. The $20 \mathrm{~nm}$ criterion was based on the estimated distance between a primary antibody and a gold tag on a secondary antibody (Paspalas and Goldman-Rakic, 2004). Organelles whose membranes were within $20 \mathrm{~nm}$ of gold particles were also traced individually.

Statistical analysis. Statistical significance ( $p$ value) was calculated using paired Student's $t$ tests (GraphPad and Excel). Data normality of all datasets was analyzed using the D'Agostino-Pearson test (GraphPad Software).

\section{Results}

\section{Localization of HA-DAT in brain slices}

To examine DAT subcellular localization in intact living dopaminergic neurons, we prepared acute sagittal brain slices from HADAT knock-in mice. Living slices cultured in ACSF were incubated with monoclonal anti-HA antibodies (HA11) for $1 \mathrm{~h}$ at room temperature, which allows labeling the cell-surface pool of HA-DAT under conditions of minimal endocytosis (Sorkina et al., 2006). After fixation, HA antibodies were detected with Cy3conjugated anti-mouse antibodies. To compare labeling of surface transporter with the total pool of transporters and with DA neurons, fixed slices were permeabilized and immunolabeled with antibodies against the DAT $\mathrm{N}$ terminus (DAT-Nt) and TH. The sections were imaged at low magnification using a large-area confocal scanning microscope to assess labeling in the entire slice 

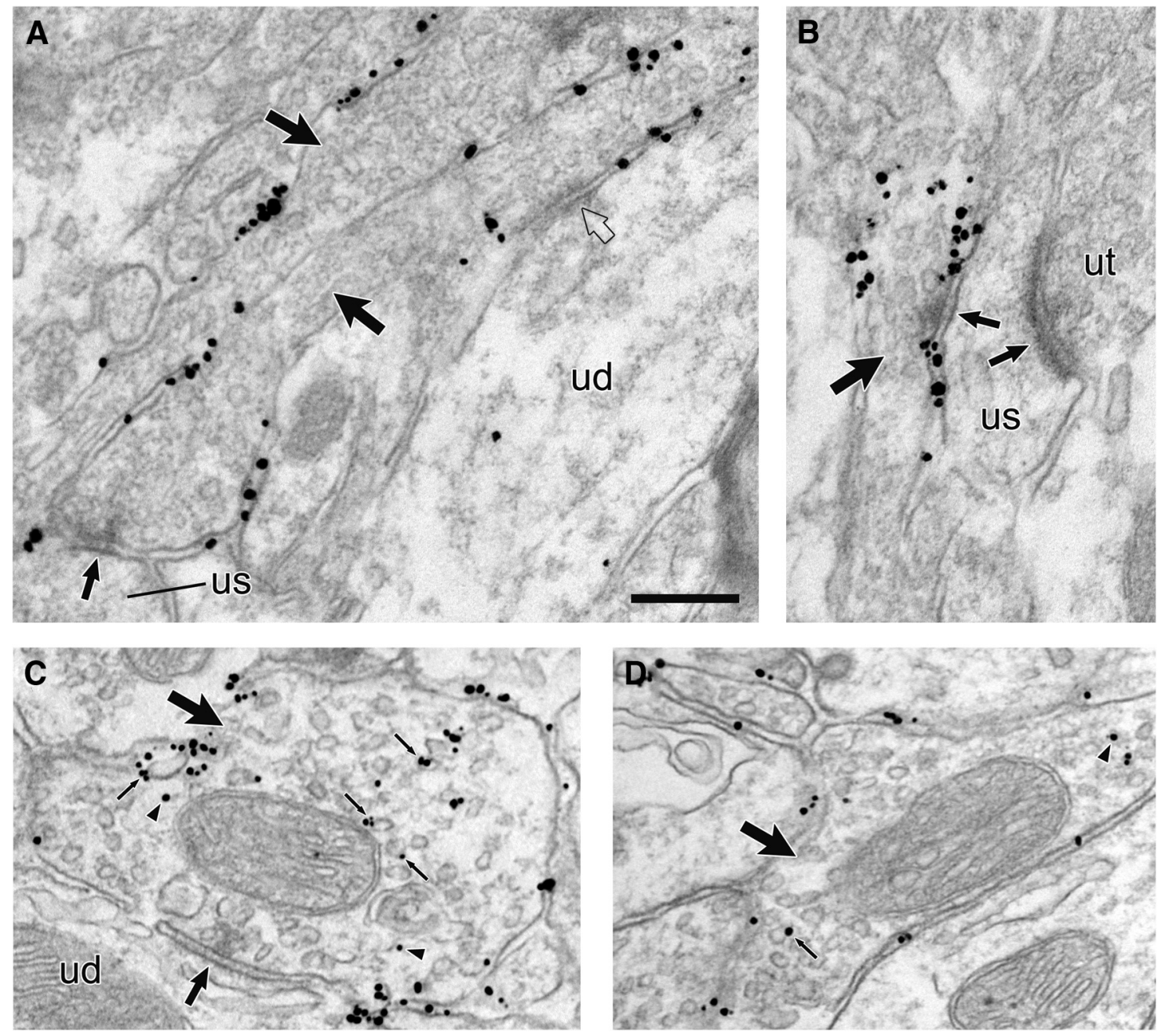

Figure 4. Distribution of HA-DAT in membrane compartments of the dorsal striatum. Electron micrographs from mouse dorsal striatum illustrating axons (large arrows) with immunogold-silver labeling for HA-DAT. In $\boldsymbol{A}$ and $\boldsymbol{B}$, particles are localized exclusively to the PM but not within the synaptic zones (medium arrows) formed onto unlabeled spines (us). One of the labeled axons in $\boldsymbol{A}$ is connected to an unlabeled dendrite (ud) by a punctum adherens (clear arrow), which also exhibits no gold-silver labeling for HA-DAT. The labeled axon in $\boldsymbol{B}$ synapses onto a spine that receives additional synaptic input from an unlabeled axon terminal (ut). In $\mathbf{C}$ and $\boldsymbol{D}$, both plasmalemmal and intracellular particles for HA-DAT are visible, the latter in association with vesicles and endosomes (small thin arrows) or with no apparent relationship to organelles (arrowheads). The axon in C synapses (medium arrow) onto an unlabeled dendrite (ud). Scale bar, $0.265 \mu \mathrm{m}$.

(Fig. 1). The labeling method directed against the HA epitope adequately labeled all of the brain areas detected by anti-DAT antibodies, and the labeling colocalized well with TH immunofluorescence in the midbrain, striatum, and neuronal tracts connecting these two areas. Of note, non-obstructive host vascular elements were detected by anti-mouse antibodies, and $\mathrm{TH}$ was also detected in norepinephrine neurons not expressing DAT. Importantly, background fluorescence of HA1 1 labeling was low in nondopaminergic areas of brain, indicating a high specificity of this labeling procedure. As expected, qualitatively, the majority of HA and DAT immunoreactivity was observed in the striatum.

Detailed 3D images from various regions of sagittal slices (typically $10-40 \mu \mathrm{m}$ deep from the surface) prepared and labeled as in Figure 1 were acquired by spinning-disk confocal microscope (Fig. 2). In the midbrain (Fig. 2A), surface HA-DAT was found on a network of processes (presumably, mostly dendrites and soma-proximal axonal segments) and varicosities (typically $\sim 2-10 \mu \mathrm{m}$ in diameter), as well as on cell bodies. Surface labeling on the cell bodies was comparatively weaker than on dendritic or axonal structures as shown by pseudocolored intensity micrographs (Fig. 2B). The DAT-Nt antibody detected all DAT, including intracellular transporters (not labeled by HA11) in cell bodies, as well as within proximal dendrites, in particular within large varicosities. In the cell bodies, the pattern of labeling with DAT-Nt antibody resembled the tubuloreticular morphology of the endoplasmic reticulum (ER), with occasional punctate structures (Fig. 2A, Midbrain insets). Interestingly, the DAT-Nt antibody was less efficient at detecting HA-DAT in the PM than in intracellular membranes, possibly because of steric hindrance of the antibody recognition site in the $\mathrm{N}$ terminus of surface transporter.

HA antibody labeling revealed a relatively homogenous distribution of the surface transporter throughout the axonal tracts between the midbrain and striatum (Fig. 2A, Tracts) and a highly complex network of axonal processes and small varicosities $(<1$ $\mu \mathrm{m}$ in diameter) in the striatum (Fig. 2A, Striatum). Labeling with DAT-Nt antibodies detected the same neuronal structures, albeit with a relatively low intensity of labeling of axonal shafts. In striatal varicosities, only few DAT-labeled structures were observed that were not also labeled with HA11, indicating a paucity of intracellular HA-DAT in this region. When the interior of striatal varicosities could be resolved, the two markers tended to colocalize at the axonal surface (Fig. 2A, Striatum insets). Quantitative analysis by pseudocolored intensity profiles (Fig. $2 B$ ) and 

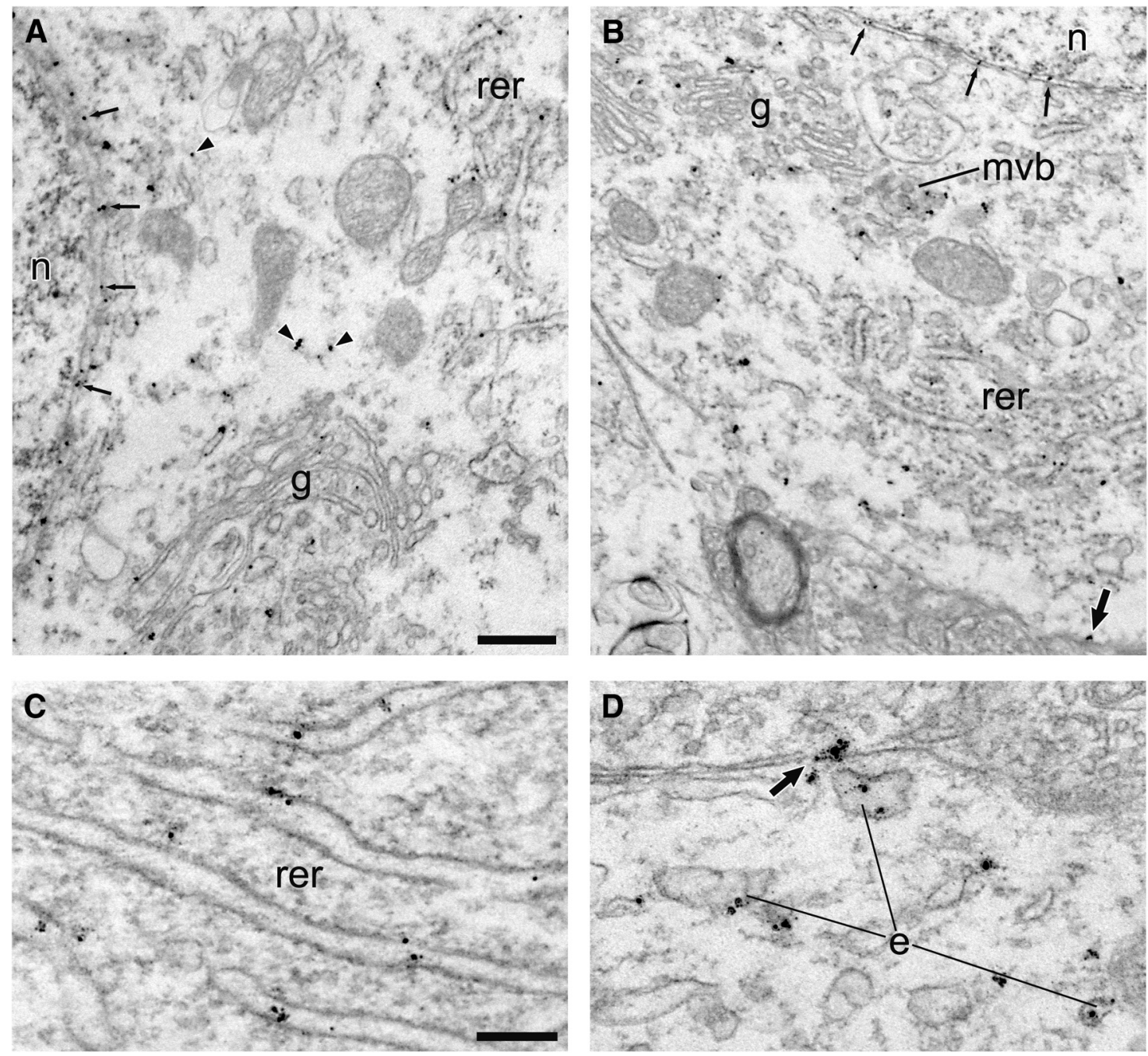

Figure 5. Localization of HA-DAT within perikarya. Electron micrographs from mouse SN illustrating the distribution of immunogold-silver labeling for HA-DAT within perikarya shown at low ( $\boldsymbol{A}$, $\boldsymbol{B}$ ) and high $(\boldsymbol{C}, \boldsymbol{D})$ magnification. Particles occur along the nuclear (n) membrane (small thin arrows) and within the Golgi apparatus ( $\mathrm{g}$ ), rough endoplasmic reticulum (rer), multivesicular bodies $(\mathrm{mvb})$, and endosomes (e). Other particles are not localized to identifiable organelles in single sections (arrowheads). A few particles appear along the PM (medium-sized arrows). Scale bars: (in $A$ ) $A, B, 0.5 \mu \mathrm{m} ;$ (in C) $C, D, 0.2 \mu \mathrm{m}$.

mean intensity calculations (Fig. 2C) revealed cell-surface HADAT in the midbrain to be $\sim 50 \%$ as dense as in the striatum and furthermore that HA-DAT in the striatum is concentrated in axonal varicosities as opposed to intervaricose segments. Together, the results in Figure 2 suggest that DAT in axons is mostly at the cell surface; in cell bodies of the midbrain, DAT can be found in surface and intracellular membranes, especially the ER. Because the total amount of DAT is much greater in the striatum, most of the DAT in the brain is therefore at the cell surface.

\section{Electron microscopic analysis of HA-DAT localization in mouse brain}

Prompted by the efficient labeling of HA-DAT in neurons of primary neuronal cultures (Rao et al., 2012) and brain slices (Figs. 1, 2), we performed EM labeling of HA-DAT in fixed mouse brain sections. Immunogold-silver labeling directed against HA11 yielded robust and efficient labeling in both the striatum (Figs. 3, 4) and midbrain SN (Figs. 5, 6), especially in mildly fixed brains (Fig. 3).

Within the striatum, HA-DAT labeling was found predominantly along the PM, in which it was notably excluded from synaptic active zones (Figs. 3, 4; Table 1). Particles for HA-DAT were less frequently found along the intracellular membranes of organelles resembling synaptic vesicles (SVs) or small endosomes (Fig. 4C,D; Table 1). In single planes of section, however, the majority of intracellular labeling had no evident organelle association, an observation that does not preclude association with organelles above or below the section plane.

For the SN, the distribution of HA-DAT immunoreactivity was typically the reverse of the striatum, with the majority of gold-silver particles being abundant along intracellular membranes, especially within somata, and with less frequent labeling at the plasmalemma (Figs. 5, 6; Table 2). Particles for HA-DAT were often observed along the nuclear membrane and membranes of the rough ER and Golgi complex (Fig. 5A-C). Labeling was also evident on putative endosomes and multivesicular bodies (Figs. 5, 6). Clathrin-coated structures were devoid of HADAT labeling in both the $\mathrm{SN}$ and the striatum. By quantitative analysis of $>600$ images (Tables 1, 2), $\sim 85 \%$ of HA-DAT bound gold particles were associated with the PM in the dorsal striatum, whereas only $\sim 25 \%$ of gold particles were associated with the plasmalemma in dendrites of the SN (soma were only qualita- 

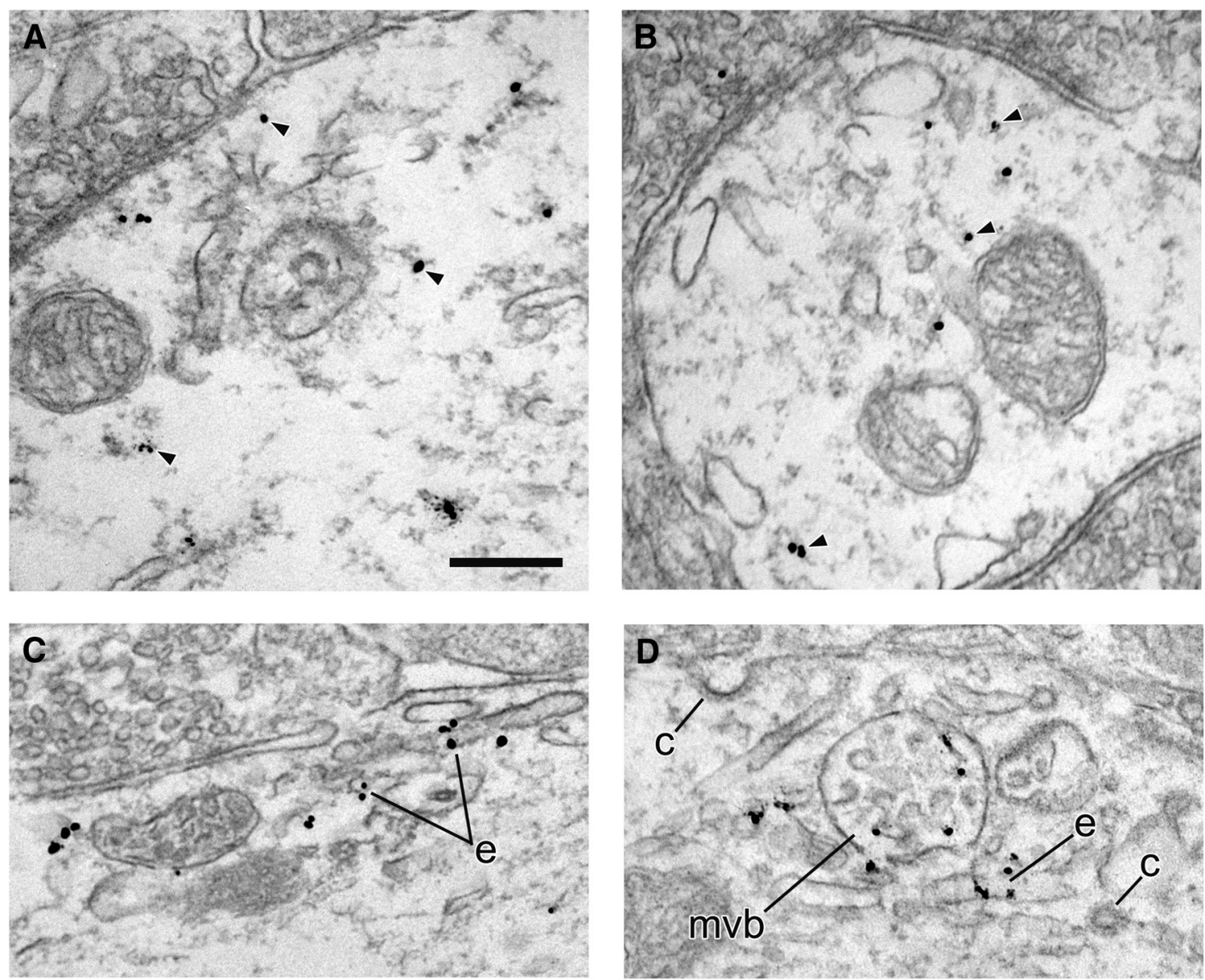

Figure 6. Localization of HA-DAT within dendrites. Electron micrographs from mouse SN illustrating immunogold-silver labeling for HA-DAT within dendrites. In $A$ and $B$, the majority of particles are not associated with identifiable structures in the cytoplasm (arrowheads) in single sections. In $\boldsymbol{C}$ and $\boldsymbol{D}$, particles are associated with specific organelles, including endosomes (e) and a multivesicular body (mvb). Note the absence of labeling near clathrin-coated vesicles (c). Scale bar, $265 \mu \mathrm{m}$.

Table 1. Quantitative EM data: axons labeled for HA-DAT in the striatum

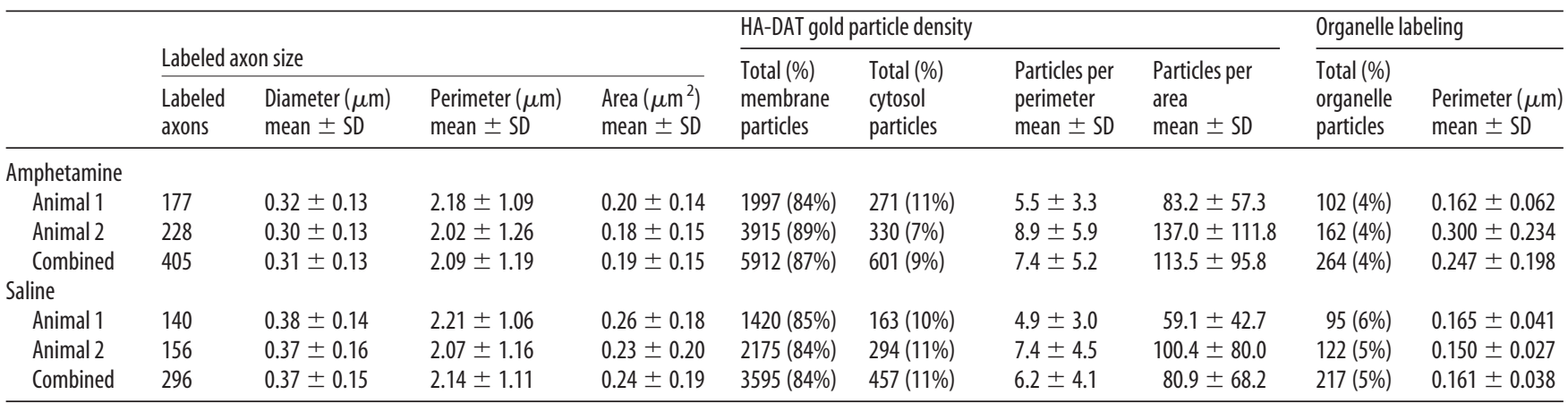

tively assessed). These EM data are in strong agreement with the observations from confocal immunofluorescence microscopy that the majority of DAT is in the PM, with an intracellular fraction that is greater in the midbrain, particularly in biosynthetic compartments.

\section{Endolysosomal compartments in dopaminergic neurons}

By confocal microscopy (Fig. 2) and EM (Figs. 3-6), DAT was localized occasionally to intracellular membranes resembling endosomes. To identify compartments containing intracellular DAT, sagittal slices from HA-DAT mice were fixed, permeabilized, and colabeled for the DAT (using either DAT-Nt antibody or HA11, depending on compatibility) and various endosomal markers (Fig. 7). The vesicular SNARE protein Stx13 regulates membrane fusion of the early and recycling endosomes on which it is found (Prekeris et al., 1998, 1999). Stx13 was detected in punctate structures within DA neuronal cell bodies that colocalized occasionally with the DAT ( 0.82 DAT/Stx 13 colocalizations/ cell; Fig. 7A). EEA.1 is a Rab5 effector and the main component of the tethering complex in early and intermediate/sorting endosomes. EEA.1 was found in punctate and tubular structures in dopaminergic cell bodies in the midbrain (Fig. $7 B$ ). As with Stx13, DAT exhibited occasional colocalization with EEA.1 in the midbrain cell bodies (0.87 DAT/EEA.1 colocalizations/cell). LAMP1 localizes mainly to late endosomes and lysosomes. Similarly to EEA.1, LAMP1 was found in punctate and tubular struc- 


\begin{tabular}{|c|c|c|c|c|c|c|c|c|c|c|}
\hline & \multirow{2}{*}{\multicolumn{4}{|c|}{ Labeled dendrite size }} & \multicolumn{4}{|c|}{ HA-DAT gold particle density } & \multicolumn{2}{|c|}{ Organelle labeling } \\
\hline & & & & & $\begin{array}{l}\text { Total }(\%) \\
\text { membrane } \\
\text { particles }\end{array}$ & $\begin{array}{l}\text { Total (\%) } \\
\text { cytosol } \\
\text { particles }\end{array}$ & $\begin{array}{l}\text { Particles per } \\
\text { perimeter } \\
\text { mean } \pm S D\end{array}$ & $\begin{array}{l}\text { Particles } \\
\text { per area } \\
\text { mean } \pm S D\end{array}$ & $\begin{array}{l}\text { Total }(\%) \\
\text { organelle } \\
\text { particles }\end{array}$ & $\begin{array}{l}\text { Perimeter } \\
(\mu \mathrm{m}) \\
\text { mean } \pm S D\end{array}$ \\
\hline Animal 1 & 68 & $1.26 \pm 0.52$ & $6.54 \pm 2.14$ & $2.62 \pm 1.69$ & $161(20 \%)$ & $533(67 \%)$ & $0.42 \pm 0.45$ & $6.3 \pm 5.28$ & $106(13 \%)$ & $0.508 \pm 0.348$ \\
\hline Animal 2 & 59 & $1.03 \pm 0.50$ & $6.64 \pm 2.33$ & $2.48 \pm 1.98$ & $167(15 \%)$ & $720(66 \%)$ & $0.49 \pm 0.46$ & $9.0 \pm 4.41$ & $211(19 \%)$ & $0.534 \pm 0.414$ \\
\hline Combined & 127 & $1.15 \pm 0.52$ & $6.58 \pm 2.22$ & $2.56 \pm 1.83$ & $328(17 \%)$ & $1253(66 \%)$ & $0.45 \pm 0.45$ & $7.5 \pm 5.06$ & $317(17 \%)$ & $0.525 \pm 0.392$ \\
\hline Animal 2 & 75 & $1.12 \pm 0.49$ & $6.18 \pm 2.34$ & $2.32 \pm 1.59$ & $244(24 \%)$ & $640(63 \%)$ & $0.61 \pm 0.68$ & $8.5 \pm 6.82$ & $128(13 \%)$ & $0.590 \pm 0.477$ \\
\hline Combined & 133 & $1.09 \pm 0.50$ & $6.35 \pm 2.41$ & $2.32 \pm 1.61$ & $524(26 \%)$ & $1207(59 \%)$ & $0.75 \pm 1.06$ & $9.5 \pm 8.43$ & $318(16 \%)$ & $0.502 \pm 0.411$ \\
\hline
\end{tabular}

tures in dopaminergic cell bodies in the midbrain (Fig. $7 C, D$ ). Despite the abundance of LAMP1 compartments in DA cell bodies, DAT was rarely observed to colocalize with LAMP1 [0.17 DAT/LAMP1 colocalizations/cell using DAT C-terminus (DATCt) antibodies to detect DAT; 0.12 DAT/LAMP1 colocalizations/ cell using HA1 1 to detect DAT]. Very few, if any, endosomes were detected in midbrain dendritic varicosities.

In the striatum, Stx13-containing endosomes were abundant in nondopaminergic cells (Fig. $8 A$ ) but were rarely detected in striatal axons and varicosities (Fig. $8 A$ detail). Because the small size of the observed structures and the resolution limits of the confocal microscopy make it difficult to conclude whether Stx13 colocalizes with the DAT in striatal axons, a super-resolution, structured illumination microscopy (SIM) was used. Lateral resolution of SIM is $\sim 100-120 \mathrm{~nm}$, which is comparable with the minimal diameter of an endosome. Although confocal imaging demonstrated overlapping DAT and Stx13 labeling, SIM imaging could clearly separate the two labels, suggesting a lack of colocalization. EEA.1 (Fig. 8C) and LAMP1 (Fig. 8D) were detected near the nuclei of nondopaminergic cells in the striatum but were not detected in striatal DA axons or in axonal tracts (Fig. 8E).

Together, these results (Figs. 2-8) suggest that DAT is expressed over the entirety of the neuronal PM (with the exception of active zones) and that the endolysosomal pool of DAT is small. This indicates that constitutive endocytosis of the transporter is rare in axon tracts and varicosities and that transporter endocytosis is slow in the somatodendritic compartment. Furthermore, endocytic colocalizations that were observed more closely resemble a recycling route of internalized DAT as opposed to sorting to the lysosomal degradation pathway. Strikingly, in DA axons, the endosomal trafficking system for DAT does not include early/ sorting endosomes.

\section{Acute administration of amphetamine does not affect subcellular distribution of HA-DAT}

Given apparently slow rates of constitutive endocytosis, we next examined whether DAT localization could be altered by stimulating endocytosis with amphetamine, an abused and therapeutic psychostimulant. Amphetamine increases monoamine neurotransmission by inducing reverse transport through reuptake transporters (Sulzer et al., 2005; Robertson et al., 2009), and it has also been shown to induce DAT endocytosis in a variety of model systems (Saunders et al., 2000; Hong and Amara 2013). HA-DAT mice were injected with $3 \mathrm{mg} / \mathrm{kg} d$-amphetamine and used for experiments after $1 \mathrm{~h}$, conditions of acute exposure known to produce marked behavioral changes (Chen et al., 2009; Rickhag et al., 2013). Quantitation after analysis by EM showed that the subcellular distribution of HA-DAT in the striatum or SN was not significantly altered from saline-injected littermate controls after a single treatment with amphetamine (Tables 1, 2; all $p$ values $\geq 0.12$, paired $t$ test, two-tailed).

To examine the effect of amphetamine treatment on DAT endocytosis in acute slice preparations ex vivo, we cultured the slices at $37^{\circ} \mathrm{C}$ for 10,30 , or 60 min with HA11 antibodies in the presence or absence of amphetamine. After fixation and permeabilization, endocytosed HA antibody could be observed by the colocalization of anti-mouse secondary antibodies with immunolabeled Stx13. In agreement with the lack of significant endocytosis in naive animals (Figs. 2-8), slices cultured in this manner exhibited no localization of HA-DAT in Stx13 endosomes, and the HA antibodies all appeared to remain at the PM (Fig. 9A, Vehicle). Treatment with $100 \mu \mathrm{M}$ amphetamine did not alter this localization (Fig. 9A, AMPH). In control experiments in HEK293 cells that stably express CFP-HA-DAT, treatment with $100 \mu \mathrm{M}$ amphetamine did induce a significant accumulation of DAT in endosomal compartments (Fig. 9B). Together, the results from fluorescence and EM suggest that, in the intact brain, a single treatment in vivo (60 $\mathrm{min})$ or ex vivo (10-60 $\mathrm{min}$ ) with amphetamine does not redistribute the DAT significantly from the PM to endosomal compartments.

\section{Discussion}

DA neurons exhibit a distinct morphology with regionally segregated axonal and somatodendritic compartments, varicosities, and unusually dense axonal arborizations. Current understanding of how DAT traffics through this complex system to regulate extracellular DA concentration is incomplete. Although numerous important studies have investigated endocytosis and subcellular distribution of DAT in heterologous cells, neuronal cultures, striatal synaptosomes (for review, see Melikian, 2004; Zahniser and Sorkin, 2009; Kristensen et al., 2011), and striatal slices (Cremona et al., 2011; Gabriel et al., 2013), few studies have examined DAT trafficking in intact neurons in the brain. In the present work, we took advantage of the HA-DAT mouse and developed a novel methodology to preserve entire DA neurons in acute sagittal slices for 3D fluorescence microscopy analysis of DAT subcellular localization and trafficking. This approach was combined with high-resolution quantitative EM analysis using preembedding immunogold-silver labeling of HA-DAT. HA antibodies labeled efficiently cell-surface and intracellular DAT, permitting quantitative analysis and localization to specific intracellular compartments. Comprehensive EM studies of DAT localization in the rat brain have established the basic model of DAT distribution over the entire DA neuron (Nirenberg et al., 1996, 1997; Hersch et al., 1997), but a number of questions remained unaddressed. Here, we have found that (1) DAT is pres- 
ent in higher concentrations in striatal axons, presynaptic terminals in particular, thus suggesting the existence of a specific targeting mechanism, and (2) there is a relatively small endolysosomal pool of DAT, which indicates the importance of both nonvesicular lateral membrane movement of the transporter, as well as PM retention mechanisms. Previous studies have determined that DAT expression levels, substrate uptake, and trafficking are unchanged by the insertion of the HA epitope and binding of HA antibodies (Sorkina et al., 2006; Eriksen et al., 2010; Rao et al., 2012), suggesting that the results of these studies with HA-DAT apply to the wild-type transporter, as well.

\section{High density of the PM DAT}

throughout the striatal axonal system

When living dopaminergic neurons were labeled with HA antibodies under conditions of negligible endocytosis to detect cellsurface DAT, the transporter was observed over the entirety of the neuron. Quantitative analysis of immunofluorescence signals revealed that cell-surface density of HA-DAT was twofold higher in striatal axons than midbrain. Moreover, by EM, the density of gold particles marking HA-DAT at the cell surface was $\sim 10$-fold higher in striatal axons than in SN dendrites. Although there were differences in the relative efficiency of somatic PM labeling in EM versus immunofluorescence, the observed low density of DAT in somatic PM agrees with previous EM observations using DAT antibodies in rat brain (Nirenberg et al., 1996, 1997) and live-cell microscopy of primary cultures (Rao et al., 2012). The mechanisms underlying this progressively increasing PM concentration of DAT (soma $<$ dendrites $<$ axons) are unknown but may involve a decreased endocytic rate or decreased membrane mobility of DAT (retention) in the areas in which DAT concentration is higher. Previous studies demonstrated that cellsurface retention of DAT is controlled by juxtamembrane amino acid residues of the DAT-Nt (Sorkina et al., 2009).

Overall, our data suggest a high density of DAT along the entire surface of axons. The absence of HA-DAT at axonal active zones observed by EM is unlikely attributable to inaccessibility of the HA epitope because similar observations were made using DAT antibodies (Hersch et al., 1997; Nirenberg et al., 1997). These observations are consistent with the "volume transmission" model suggested for nigrostriatal projections whereby DAT regulates the range and magnitude of extrasynaptic DA signaling (Cragg et al., 2004; Rice and Cragg, 2008) to modulate multiple neurons over a large physical space (Arbuthnott and Wickens, 2007; Rice et al., 2011). Although DAT is
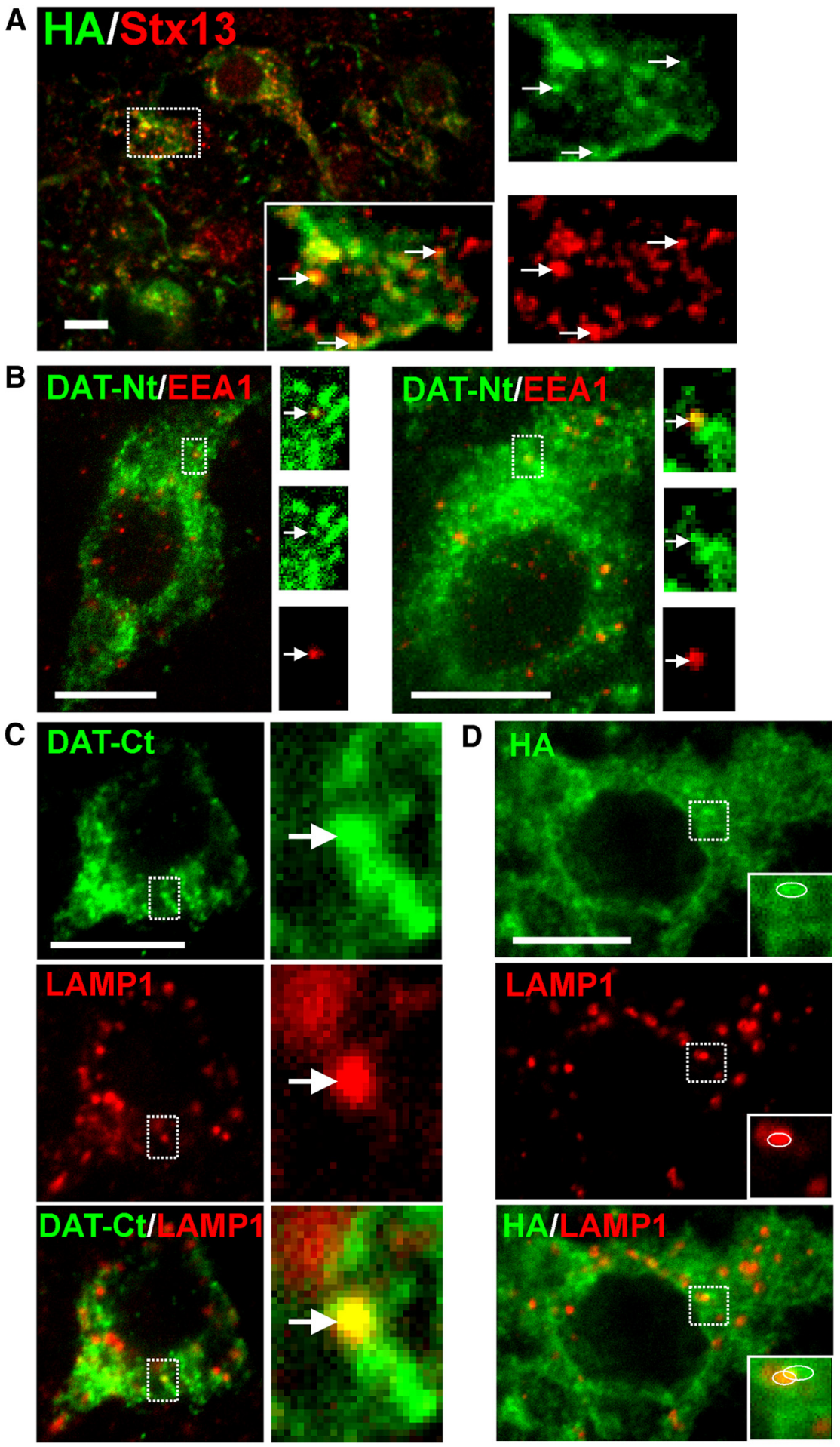

Figure 7. Colocalization of DAT with endosomal markers in midbrain. Slices were fixed, permeabilized, and labeled with antibodies against HA and Stx13 (A), DAT-Nt and EEA.1 (B), DAT-Ct and LAMP1 (C), or HA and LAMP1 (D), followed by fluorophoreconjugated secondary antibodies. DAT is shown in green, and endosomal markers are shown in red. Maximum-intensity projections of two to three consecutive confocal sections from the collected $z$ stacks of the midbrain are presented. Insets show high-magnification images of areas indicated by white rectangles. Arrows show examples of colocalization. Inset in C shows an example of localization of HA-DAT in a LAMP1-containing compartment. An example of partial overlap of DAT- and LAMP1-containing structures illustrating lack of true colocalization in insets $(\boldsymbol{D})$ is indicated by circles. Scale bars, $10 \mu \mathrm{m}$.

certainly expressed over the entire DA neuron, we have found here that, in the striatal axonal network, the mean fluorescence intensity of surface HA-DAT was higher in varicosities than intervaricose shafts. This increase in DAT density at putative presynaptic 
A
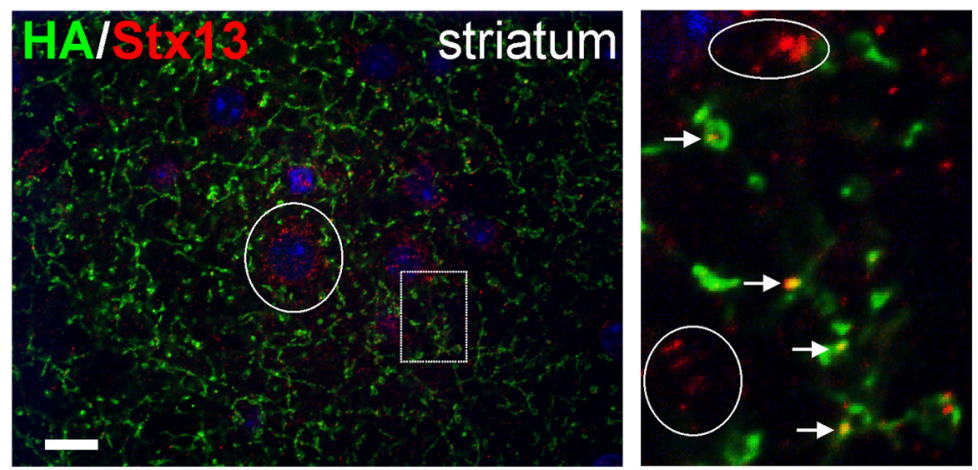

B

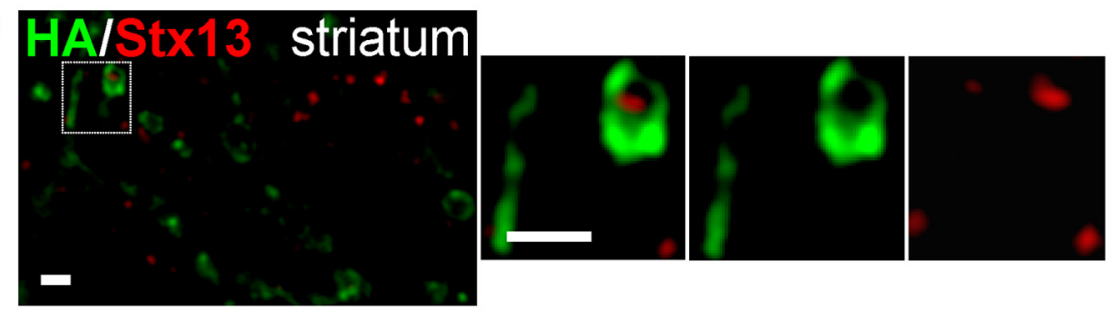

C

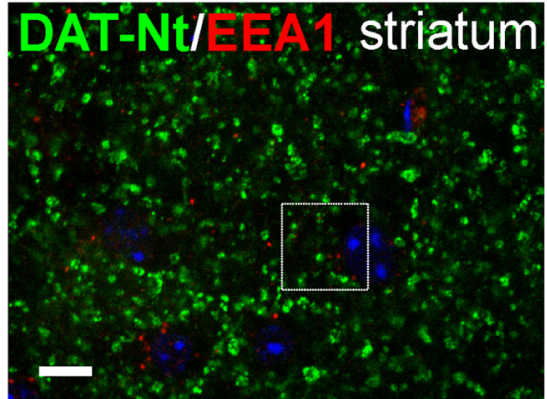

D

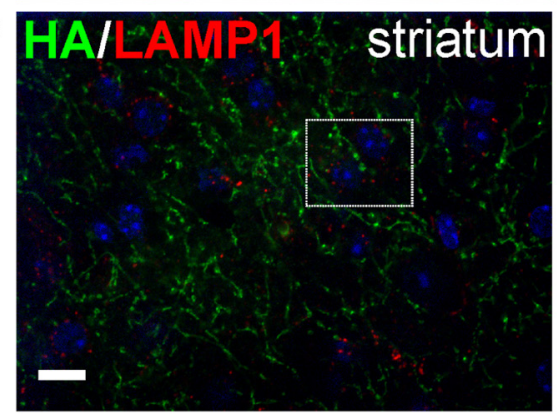

E
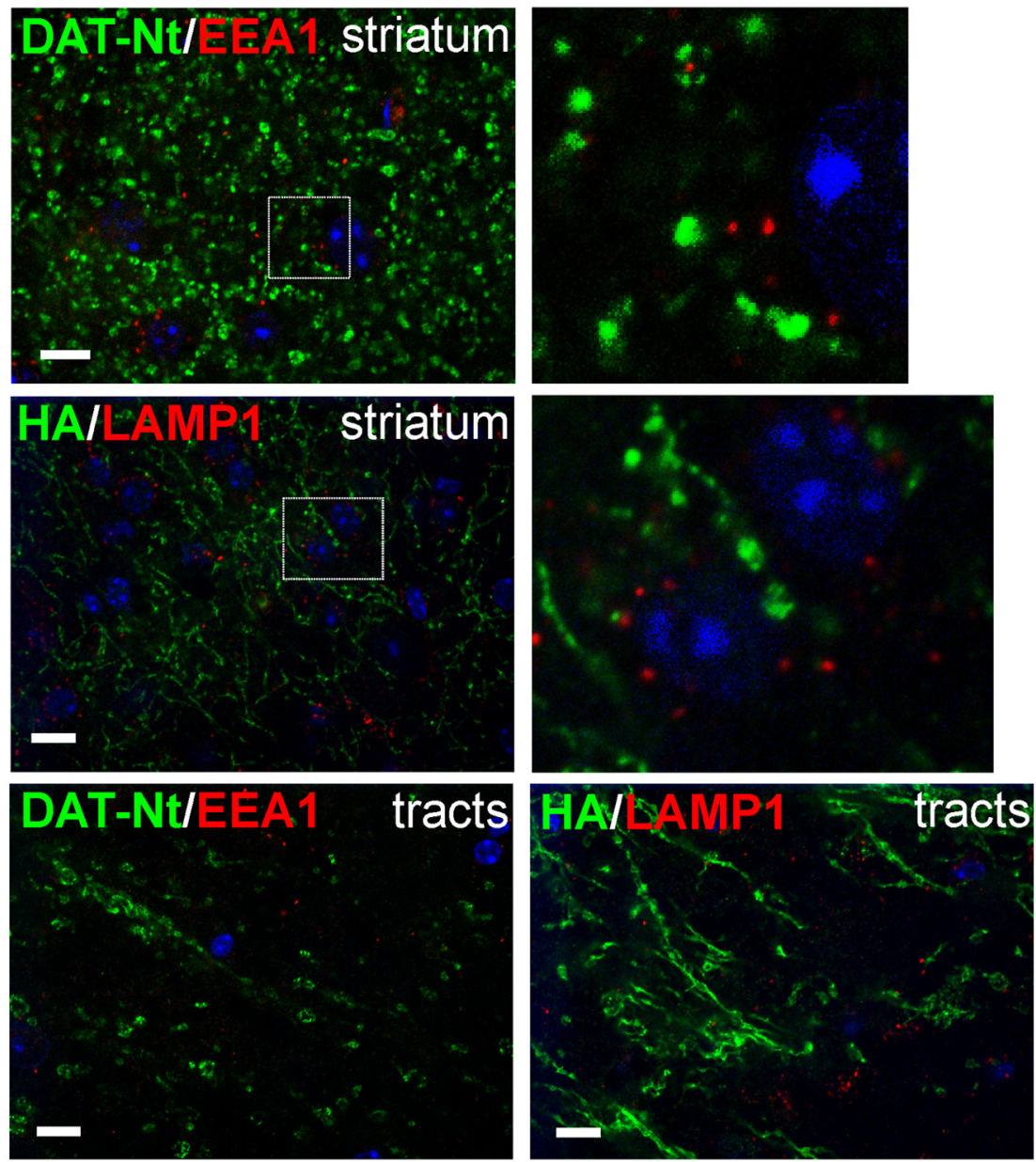

Figure 8. Lack of early and late endosomes in tracts and striatal axons of DA neurons. Slices were fixed, permeabilized, and labeled with antibodies against HA and Stx13 $(\boldsymbol{A}, \boldsymbol{B})$, DAT-Nt and EEA.1 $(\boldsymbol{C}, \boldsymbol{E})$, or HA and LAMP1 $(\boldsymbol{D}, \boldsymbol{E})$ followed by fluorophoreconjugated secondary antibodies. DAT is shown in green, and endosomal markers are shown in red. Images were acquired by spinning-disk confocal $(\boldsymbol{A}, \boldsymbol{C}-\boldsymbol{E})$ or SIM $(\boldsymbol{B})$ systems. Maximum-intensity projections of two to three consecutive confocal sections from the collected $z$ stacks of the striatum $(\boldsymbol{A}, \boldsymbol{C}, \boldsymbol{D})$ and tracts $(\boldsymbol{E})$ are presented. Single optical section is presented in $\boldsymbol{B}$. Highmagnification images of areas indicated by white rectangles are shown on the right. In $A$, arrows show examples of overlap of $S t x 13$ and DAT fluorescence in axonal varicosities. The presence of a large number of Stx 13 endosomes in nondopaminergic cells is indicated by circles. For $\boldsymbol{B}$, SIM imaging of the striatum in slices processed as in $A$ is shown; no overlap of DAT and Stx13 labeling was observed within the varicosity. In $\boldsymbol{C}$ and $\boldsymbol{D}$, high-magnification images show abundance of EEA.1 and LAMP1 compartments, respectively, in nondopaminergic cells. Scale bars: $\boldsymbol{A}, \boldsymbol{C}-\boldsymbol{E}, 10 \mu \mathrm{m} ; \boldsymbol{B}, 1 \mu \mathrm{m}$. areas suggests that DA reuptake, like release, is in fact spatially regulated.

\section{Low levels of DAT endocytosis in axonal and somatodendritic compartments}

Quantitative EM showed that $\sim 84 \%$ of gold particles were at the cell surface, whereas only $5 \%$ were associated clearly with intracellular membranes in striatal axons examined in single sections. Consistently, no endosomes containing HADAT together with markers of early, recycling, or late endosomes were found in the striatum by immunofluorescence. Stx13-positive endosomes have been described in axons of other neurons (Prekeris et al., 1999) and cultured DA neurons (Rao et al., 2012). However, in the present studies, Stx13-positive structures were detected rarely in DA axons. Interestingly, when synaptic areas were resolved by EM, intracellular HA-DAT was associated more frequently with structures of the size and morphology of SVs rather than with larger, endosomelike compartments. In contrast, previous subcellular fractionation studies of rat striatum did not identify DAT in the SV fraction, likely because the SV pool of DAT is small (Rao et al., 2011). Our data present an alternative interpretation to studies in which significant pools of intracellular transporters $(\sim 40 \%)$ have been detected by surface biotinylation or striatal membrane fractionation (Johnson et al., 2005; Richards and Zahniser, 2009; German et al., 2012). Surface biotinylation of synaptosomal preparations may underestimate the PM pool because of limited biotinylation efficiency, and organelle fractionation does not cleanly separate early endosomes from the PM. The relative paucity of intracellular axonal DAT detected in the present studies is also inconsistent with models describing rapid delivery of a large intracellular pool of transporters to the PM during stimulation (Johnson et al., 2005; Furman et al., 2009).

In $\mathrm{SN}$ dendrites analyzed by EM, only $\sim 25 \%$ of DAT was at the cell surface. Echoing previous studies (Nirenberg et al., 1996, 1997; Hersch et al., 1997), EM detected a significant intracellular pool of transporters in somatodendritic regions in rough ER and Golgi, whereas only a small pool of DAT was located in membrane compartments with endosome-like morphology, including multivesicular bodies. This EM analysis, together with immunofluorescence colocalization studies that demonstrated a higher extent of DAT localization in Stx13- and EEA.1- 


\section{A Vehicle: $10 \mathrm{~min}$}
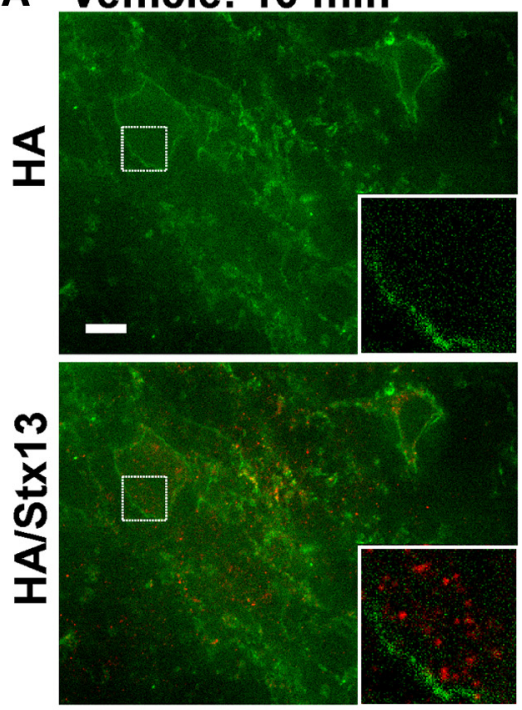

AMPH: $10 \mathrm{~min}$
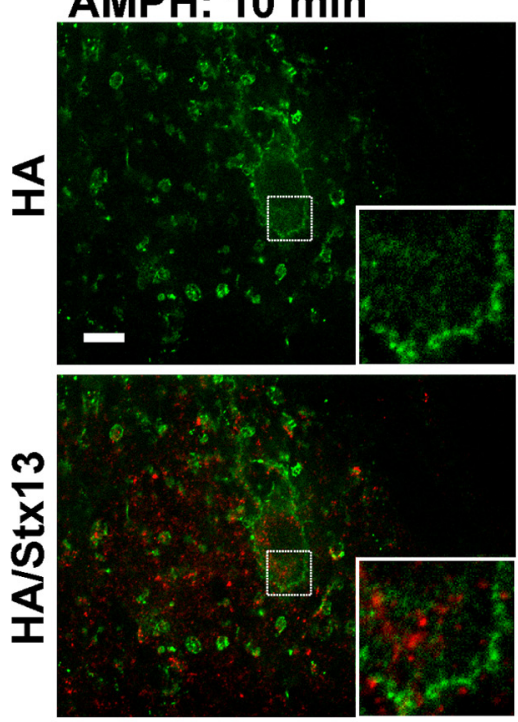

B

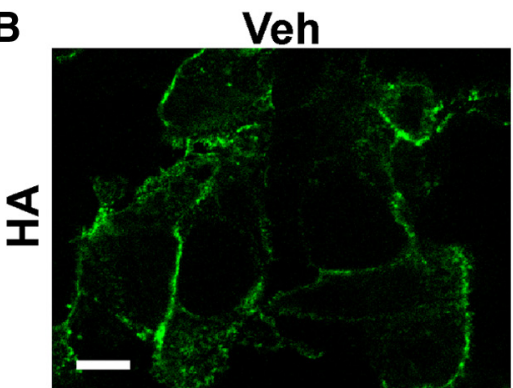

$30 \mathrm{~min}$
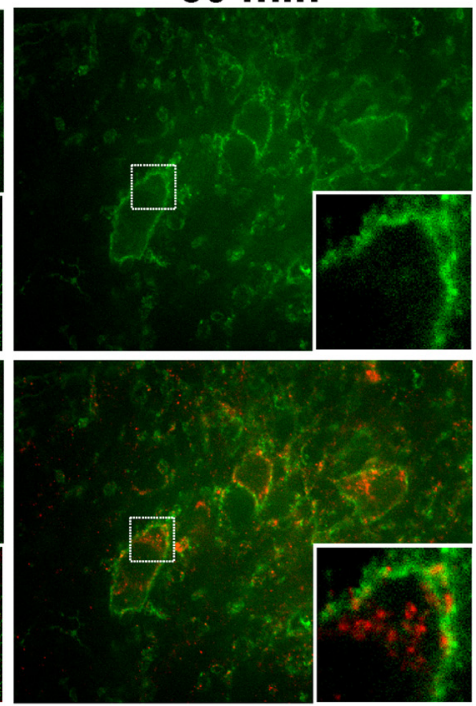

$30 \mathrm{~min}$
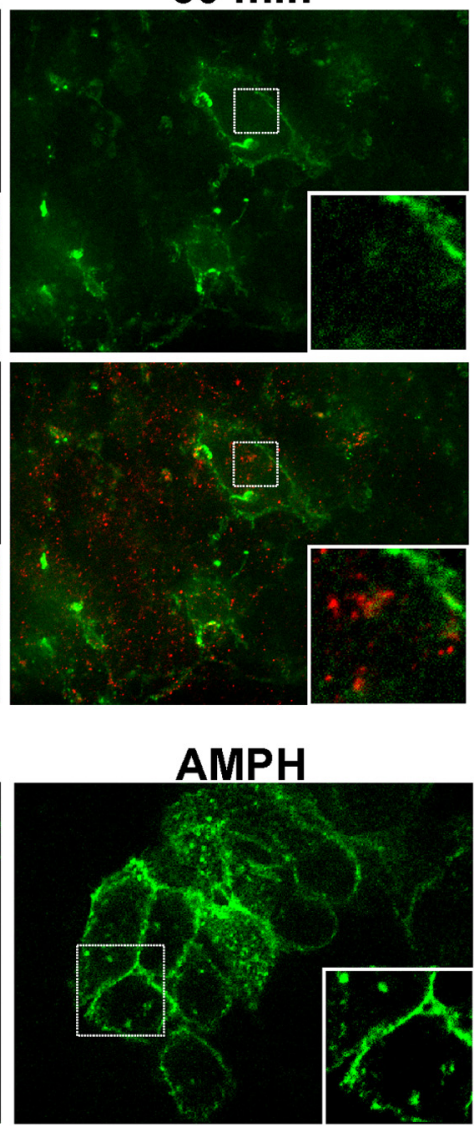

$60 \mathrm{~min}$
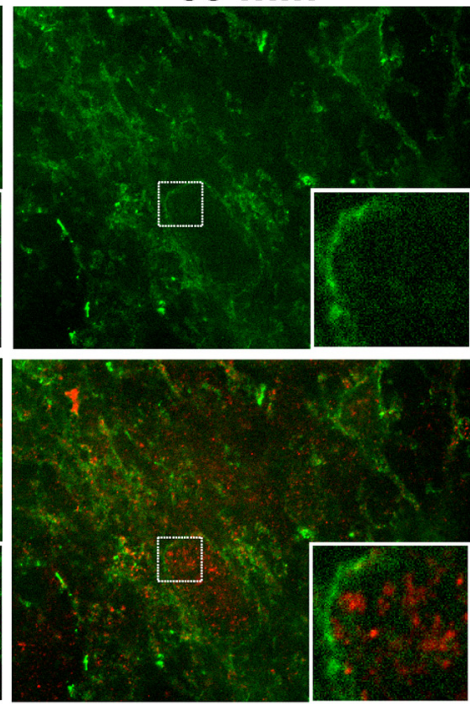

$60 \mathrm{~min}$
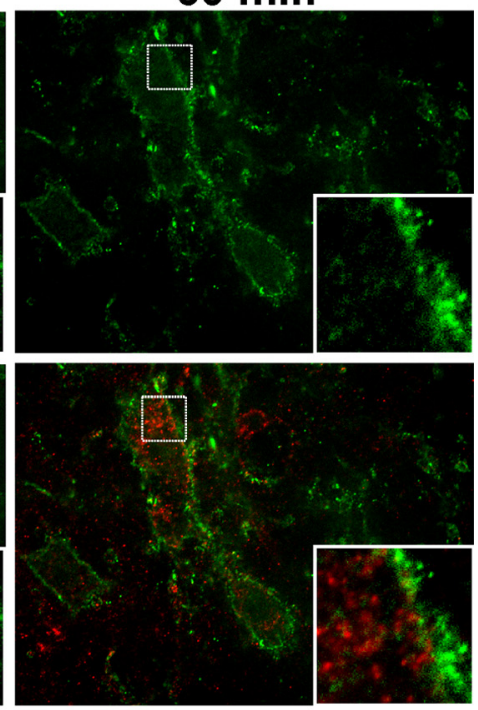

Figure 9. Amphetamine does not affect subcellular distribution of DAT. A, Acute slices were incubated with HA11 and either vehicle or 100 $\mu$ m amphetamine (AMPH) for 10, 30, or 60 min at $37^{\circ} \mathrm{C}$. Slices were then fixed, permeabilized, and labeled with the Stx 13 antibody, followed up by secondary antibodies labeled with Cy5 (HA-DAT, green) and Cy3 (Stx13, red). 3D image acquisition was performed through $561 \mathrm{~nm}$ and $640 \mathrm{~nm}$ channels. Individual optical sections are presented. Insets are high-magnification images of the regions indicated by white rectangles showing parts of the soma. $\boldsymbol{B}$, HEK293 cells expressing CFP-HA-DAT were incubated with HA11 and either vehicle or $100 \mu \mathrm{m}$ amphetamine for 30 min at $37^{\circ} \mathrm{C}$. Cells were fixed and labeled to detect HA-DAT as in $\boldsymbol{A}$ before imaging. Insets show high magnification of the region indicated by white rectangle to show examples of amphetamine-induced endosomes. Scale bars, $10 \mu \mathrm{m}$.

positive than in LAMP1-postive compartments in somata suggests that endocytosed DAT tends to traffic toward recycling pathways as opposed to lysosomal degradation. Studies with primary cultures of DA neurons have also observed transporter in early and recycling compartments but have detected a significant pool of DAT in late endosomes (Eriksen et al., 2010; Rao et al., 2011). These discrepancies suggest that trafficking and degradation of DAT in cell culture and brain may be fundamentally different and highlight the need for continued investigations into trafficking mechanisms in intact neurons in the brain. 


\section{Acute administration of amphetamine does not increase DAT endocytosis}

High-efficiency labeling of HA-DAT in the present EM studies permitted a quantitative approach to investigate the effect of acute in vivo amphetamine treatment on DAT distribution. Amphetamine has been shown to induce DAT endocytosis or inhibit DA uptake in models that include cultured neurons (Hong and Amara, 2013), synaptosomes (Johnson et al., 2005; Richards and Zahniser, 2009), and heterologous cells (Saunders et al., 2000). Amphetamine doses administered in vivo or to slices in the present studies correspond to doses used in single-treatment experiments in which DAT endocytosis and other effects of amphetamine were observed (Chen et al., 2009; Richards and Zahniser, 2009; Rickhag et al., 2013). However, we did not detect any changes in subcellular localization of DAT in striatal axons or SN dendrites by EM. Furthermore, treating acute slices with amphetamine for 10-60 min did not stimulate endocytosis in any region of DA neurons. Although methods used in the present study may not be sensitive enough to detect rapid and small changes in DAT endocytosis, our data are in agreement with findings that acute amphetamine treatment does not stimulate substantial DAT endocytosis in intact systems (German et al., 2012).

\section{Conclusions}

The steady-state subcellular localization of DAT in the striatum is consistent with the endocytosis rate being five to six times lower than the recycling rate, kinetics characteristic of a PM-retained cargo, such as inactive growth factor receptors (Sorkin and Goh, 2009). DAT is routed through conventional endocytic pathways in the somatodendritic region, but this trafficking activity is of a small scale. Although dopaminergic neurons seem to possess the necessary machinery for a normal itinerary of membrane traffic in the somatodendritic compartment, the lack of conventional endosomes in axons is striking. We hypothesize that the majority of DAT is not transported via vesicular trafficking mechanisms. Rather, in the intact brain, DAT is more likely transported between midbrain and striatum by lateral diffusion in the PM. This is consistent with measurements of DAT half-life using radioactive tracers in intact rat brains, estimated to be $\sim 2-6 \mathrm{~d}$ (Fleckenstein et al., 1996; Kimmel et al., 2000), which is orders of magnitude longer than the half-life of cell-surface DAT observed in heterologous expression systems (Boudanova et al., 2008). The present study illustrates the potential of sagittal slice preparations to define the kinetics and physiological mechanisms of DAT trafficking and turnover.

\section{References}

Arbuthnott GW, Wickens J (2007) Space, time and dopamine. Trends Neurosci 30:62-69. CrossRef Medline

Boudanova E, Navaroli DM, Melikian HE (2008) Amphetamine-induced decreases in dopamine transporter surface expression are protein kinase C-independent. Neuropharmacology 54:605-612. CrossRef Medline

Chen JW, Pan W, D'Souza MP, August JT (1985) Lysosome-associated membrane proteins: characterization of LAMP-1 of macrophage P388 and mouse embryo 3T3 cultured cells. Arch Biochem Biophys 239:574586. CrossRef Medline

Chen R, Furman CA, Zhang M, Kim MN, Gereau RW 4th, Leitges M, Gnegy ME (2009) Protein kinase Cbeta is a critical regulator of dopamine transporter trafficking and regulates the behavioral response to amphetamine in mice. J Pharmacol Exp Ther 328:912-920. CrossRef Medline

Chen R, Furman CA, Gnegy ME (2010) Dopamine transporter trafficking: rapid response on demand. Future Neurol 5:123. CrossRef Medline

Ciliax BJ, Drash GW, Staley JK, Haber S, Mobley CJ, Miller GW, Mufson EJ, Mash DC, Levey AI (1999) Immunocytochemical localization of the dopamine transporter in human brain. J Comp Neurol 409:38-56. CrossRef Medline
Cragg SJ, Baufreton J, Xue Y, Bolam JP, Bevan MD (2004) Synaptic release of dopamine in the subthalamic nucleus. Eur J Neurosci 20:1788-1802. CrossRef Medline

Cremona ML, Matthies HJ, Pau K, Bowton E, Speed N, Lute BJ, Anderson M, Sen N, Robertson SD, Vaughan RA, Rothman JE, Galli A, Javitch JA, Yamamoto A (2011) Flotillin-1 is essential for PKC-triggered endocytosis and membrane microdomain localization of DAT. Nat Neurosci 14: 469-477. CrossRef Medline

Eriksen J, Rasmussen SG, Rasmussen TN, Vaegter CB, Cha JH, Zou MF, Newman AH, Gether U (2009) Visualization of dopamine transporter trafficking in live neurons by use of fluorescent cocaine analogs. J Neurosci 29:6794-6808. CrossRef Medline

Eriksen J, Bjørn-Yoshimoto WE, Jørgensen TN, Newman AH, Gether U (2010) Postendocytic sorting of constitutively internalized dopamine transporter in cell lines and dopaminergic neurons. J Biol Chem 285: 27289-27301. CrossRef Medline

Fleckenstein AE, Pögün S, Carroll FI, Kuhar MJ (1996) Recovery of dopamine transporter binding and function after intrastriatal administration of the irreversible inhibitor RTI-76 [ 3 beta-(3p-chlorophenyl) tropan-2 beta-carboxylic acid p-isothiocyanatophenylethyl ester hydrochloride]. J Pharmacol Exp Ther 279:200-206. Medline

Furman CA, Chen R, Guptaroy B, Zhang M, Holz RW, Gnegy M (2009) Dopamine and amphetamine rapidly increase dopamine transporter trafficking to the surface: live-cell imaging using total internal reflection fluorescence microscopy. J Neurosci 29:3328-3336. CrossRef Medline

Gabriel LR, Wu S, Kearney P, Bellvé KD, Standley C, Fogarty KE, Melikian HE (2013) Dopamine transporter endocytic trafficking in striatal dopaminergic neurons: differential dependence on dynamin and the actin cytoskeleton. J Neurosci 33:17836-17846. CrossRef Medline

Gainetdinov RR, Caron MG (2003) Monoamine transporters: from genes to behavior. Annu Rev Pharmacol Toxicol 43:261-284. CrossRef Medline

Garzón M, Pickel VM (2006) Subcellular distribution of M2 muscarinic receptors in relation to dopaminergic neurons of the rat ventral tegmental area. J Comp Neurol 498:821-839. CrossRef Medline

German CL, Hanson GR, Fleckenstein AE (2012) Amphetamine and methamphetamine reduce striatal dopamine transporter function without concurrent dopamine transporter relocalization. J Neurochem 123:288 297. CrossRef Medline

Giros B, el Mestikawy S, Bertrand L, Caron MG (1991) Cloning and functional characterization of a cocaine-sensitive dopamine transporter. FEBS Lett 295:149-154. CrossRef Medline

Hersch SM, Yi H, Heilman CJ, Edwards RH, Levey AI (1997) Subcellular localization and molecular topology of the dopamine transporter in the striatum and substantia nigra. J Comp Neurol 388:211-227. CrossRef Medline

Hong WC, Amara SG (2013) Differential targeting of the dopamine transporter to recycling or degradative pathways during amphetamine- or PKC-regulated endocytosis in dopamine neurons. FASEB J 27:29953007. CrossRef Medline

Hoover BR, Everett CV, Sorkin A, Zahniser NR (2007) Rapid regulation of dopamine transporters by tyrosine kinases in rat neuronal preparations. J Neurochem 101:1258-1271. CrossRef Medline

Huff RA, Vaughan RA, Kuhar MJ, Uhl GR (1997) Phorbol esters increase dopamine transporter phosphorylation and decrease transport Vmax. J Neurochem 68:225-232. CrossRef Medline

Jaber M, Jones S, Giros B, Caron MG (1997) The dopamine transporter: a crucial component regulating dopamine transmission. Mov Disord 12: 629-633. CrossRef Medline

Johnson LA, Furman CA, Zhang M, Guptaroy B, Gnegy ME (2005) Rapid delivery of the dopamine transporter to the plasmalemmal membrane upon amphetamine stimulation. Neuropharmacology 49:750-758. CrossRef Medline

Kimmel HL, Carroll FI, Kuhar MJ (2000) Dopamine transporter synthesis and degradation rate in rat striatum and nucleus accumbens using RTI-76. Neuropharmacology 39:578-585. CrossRef Medline

Kristensen AS, Andersen J, Jørgensen TN, Sørensen L, Eriksen J, Loland CJ, Strømgaard K, Gether U (2011) SLC6 neurotransmitter transporters: structure, function, and regulation. Pharmacol Rev 63:585-640. CrossRef Medline

Melikian HE (2004) Neurotransmitter transporter trafficking: endocytosis, recycling, and regulation. Pharmacol Ther 104:17-27. CrossRef Medline

Melikian HE, Buckley KM (1999) Membrane trafficking regulates the activity of the human dopamine transporter. J Neurosci 19:7699-7710. Medline 
Miranda M, Sorkina T, Grammatopoulos TN, Zawada WM, Sorkin A (2004) Multiple molecular determinants in the carboxyl terminus regulate dopamine transporter export from endoplasmic reticulum. J Biol Chem 279: 30760-30770. CrossRef Medline

Mu FT, Callaghan JM, Steele-Mortimer O, Stenmark H, Parton RG, Campbell PL, McCluskey J, Yeo JP, Tock EP, Toh BH (1995) EEA.1, an early endosome-associated protein. EEA.1 ia a conserved a-helical peripheral membrane protein flanked by cysteine "fingers" and contains a calmodulin-binding IQ motif. J Biol Chem 270:13503-13511. CrossRef Medline

Nirenberg MJ, Vaughan RA, Uhl GR, Kuhar MJ, Pickel VM (1996) The dopamine transporter is localized to dendritic and axonal plasma membranes of nigrostriatal dopaminergic neurons. J Neurosci 16:436-447. Medline

Nirenberg MJ, Chan J, Vaughan RA, Uhl GR, Kuhar MJ, Pickel VM (1997) Immunogold localization of the dopamine transporter: an ultrastructural study of the rat ventral tegmental area. J Neurosci 17:5255-5262. Medline

Paspalas CD, Goldman-Rakic PS (2004) Microdomains for dopamine volume neurotransmission in primate prefrontal cortex. J Neurosci 24:52925300. CrossRef Medline

Prekeris R, Klumperman J, Chen YA, Scheller RH (1998) Syntaxin 13 mediates cycling of plasma membrane proteins via tubulovesicular recycling endosomes. J Cell Biol 143:957-971. CrossRef Medline

Prekeris R, Foletti DL, Scheller RH (1999) Dynamics of tubulovesicular recycling endosomes in hippocampal neurons. J Neurosci 19:10324-10337. Medline

Rao A, Simmons D, Sorkin A (2011) Differential subcellular distribution of endosomal compartments and the dopamine transporter in dopaminergic neurons. Mol Cell Neurosci 46:148-158. CrossRef Medline

Rao A, Richards TL, Simmons D, Zahniser NR, Sorkin A (2012) Epitopetagged dopamine transporter knock-in mice reveal rapid endocytic trafficking and filopodia targeting of the transporter in dopaminergic axons. FASEB J 26:1921-1933. CrossRef Medline

Rice ME, Cragg SJ (2008) Dopamine spillover after quantal release: rethinking dopamine transmission in the nigrostriatal pathway. Brain Res Rev 58:303-313. CrossRef Medline

Rice ME, Patel JC, Cragg SJ (2011) Dopamine release in the basal ganglia. Neuroscience 198:112-137. CrossRef Medline

Richards TL, Zahniser NR (2009) Rapid substrate-induced downregulation in function and surface localization of dopamine transporters: rat dorsal striatum versus nucleus accumbens. J Neurochem 108:15751584. CrossRef Medline

Rickhag M, Hansen FH, Sørensen G, Strandfelt KN, Andresen B, Gotfryd K, Madsen KL, Vestergaard-Klewe I, Ammendrup-Johnsen I, Eriksen J, Newman AH, Füchtbauer EM, Gomeza J, Woldbye DP, Wörtwein G, Gether U (2013) A C-terminal PDZ domain-binding sequence is required for striatal distribution of the dopamine transporter. Nat Commun 4:1580. CrossRef Medline
Robertson SD, Matthies HJ, Galli A (2009) A closer look at amphetamineinduced reverse transport and trafficking of the dopamine and norepinephrine transporters. Mol Neurobiol 39:73-80. CrossRef Medline

Salvatore MF, Apparsundaram S, Gerhardt GA (2003) Decreased plasma membrane expression of striatal dopamine transporter in aging. Neurobiol Aging 24:1147-1154. CrossRef Medline

Saunders C, Ferrer JV, Shi L, Chen J, Merrill G, Lamb ME, Leeb-Lundberg LM, Carvelli L, Javitch JA, Galli A (2000) Amphetamine-induced loss of human dopamine transporter activity: an internalization-dependent and cocaine-sensitive mechanism. Proc Natl Acad Sci U S A 97:6850-6855. CrossRef Medline

Sesack SR, Hawrylak VA, Matus C, Guido MA, Levey AI (1998) Dopamine axon varicosities in the prelimbic division of the rat prefrontal cortex exhibit sparse immunoreactivity for the dopamine transporter. J Neurosci 18:2697-2708. Medline

Sorkin A, Goh LK (2009) Endocytosis and intracellular trafficking of ErbBs. Exp Cell Res 315:683-696. CrossRef Medline

Sorkina T, Miranda M, Dionne KR, Hoover BR, Zahniser NR, Sorkin A (2006) RNA interference screen reveals an essential role of Nedd4-2 in dopamine transporter ubiquitination and endocytosis. J Neurosci 26 : 8195-8205. CrossRef Medline

Sorkina T, Richards TL, Rao A, Zahniser NR, Sorkin A (2009) Negative regulation of dopamine transporter endocytosis by membrane-proximal N-terminal residues. J Neurosci 29:1361-1374. CrossRef Medline

Spiga S, Lintas A, Diana M (2008) Addiction and cognitive functions. Ann N Y Acad Sci 1139:299-306. CrossRef Medline

Sulzer D, Sonders MS, Poulsen NW, Galli A (2005) Mechanisms of neurotransmitter release by amphetamines: a review. Prog Neurobiol 75: 406-433. CrossRef Medline

Vaughan RA, HuffRA, Uhl GR, Kuhar MJ (1997) Protein kinase C-mediated phosphorylation and functional regulation of dopamine transporters in striatal synaptosomes. J Biol Chem 272:15541-15546. CrossRef Medline

Veznedaroglu E, Milner TA (1992) Elimination of artifactual labeling of hippocampal mossy fibers seen following pre-embedding immunogoldsilver technique by pretreatment with zinc chelator. Microsc Res Tech 23:100-101. CrossRef Medline

Vina-Vilaseca A, Sorkin A (2010) Lysine 63-linked polyubiquitination of the dopamine transporter requires WW3 and WW4 domains of Nedd4-2 and UBE2D ubiquitin-conjugating enzymes. J Biol Chem 285:7645-7656. CrossRef Medline

Willuhn I, Wanat MJ, Clark JJ, Phillips PE (2010) Dopamine signaling in the nucleus accumbens of animals self-administering drugs of abuse. Curr Top Behav Neurosci 3:29-71. CrossRef Medline

Wise RA (2008) Dopamine and reward: the anhedonia hypothesis 30 years on. Neurotox Res 14:169-183. CrossRef Medline

Zahniser NR, Sorkin A (2009) Trafficking of dopamine transporters in psychostimulant actions. Semin Cell Dev Biol 20:411-417. CrossRef Medline 